ARTICLE

https://doi.org/10.1038/s41467-019-08353-4

\title{
Template-directed RNA polymerization and enhanced ribozyme catalysis inside membraneless compartments formed by coacervates
}

\author{
Raghav R. Poudyal ${ }^{1,2}$, Rebecca M. Guth-Metzler ${ }^{3,4}$, Andrew J. Veenis ${ }^{1,2}$, Erica A. Frankel ${ }^{1,2,5}$, \\ Christine D. Keating ${ }^{1} \&$ Philip C. Bevilacqua ${ }^{1,2,3}$
}

Membraneless compartments, such as complex coacervates, have been hypothesized as plausible prebiotic micro-compartments due to their ability to sequester RNA; however, their compatibility with essential RNA World chemistries is unclear. We show that such compartments can enhance key prebiotically-relevant RNA chemistries. We demonstrate that template-directed RNA polymerization is sensitive to polycation identity, with polydiallyldimethylammonium chloride (PDAC) outperforming poly(allylamine), poly(lysine), and poly(arginine) in polycation/RNA coacervates. Differences in RNA diffusion rates between PDAC/RNA and oligoarginine/RNA coacervates imply distinct biophysical environments. Template-directed RNA polymerization is relatively insensitive to $\mathrm{Mg}^{2+}$ concentration when performed in PDAC/RNA coacervates as compared to buffer, even enabling partial rescue of the reaction in the absence of magnesium. Finally, we show enhanced activities of multiple nucleic acid enzymes including two ribozymes and a deoxyribozyme, underscoring the generality of this approach, in which functional nucleic acids like aptamers and ribozymes, and in some cases key cosolutes localize within the coacervate microenvironments.

\footnotetext{
${ }^{1}$ Department of Chemistry, The Pennsylvania State University, University Park, PA 16802, USA. ${ }^{2}$ Center for RNA Molecular Biology, The Pennsylvania State University, University Park, PA 16802, USA. ${ }^{3}$ Department of Biochemistry, Microbiology, and Molecular Biology, The Pennsylvania State University, University Park, PA 16802, USA. ${ }^{4}$ Present address: School of Chemistry and Biochemistry, Georgia Institute of Technology, Atlanta, GA 30332, USA. ${ }^{5}$ Present address: The Dow Chemical Company, 400 Arcola Road, Collegeville, PA 19426, USA. Correspondence and requests for materials should be addressed to R.R.P. (email: rup34@psu.edu) or to C.D.K. (email: keating@chem.psu.edu) or to P.C.B. (email: pcb5@psu.edu)
} 
T he RNA world hypothesis posits roles for RNA as catalysts and carriers of genetic information on the primordial Earth $^{1,2}$. Discovery of multiple natural and artificial ribozymes and aptamers has demonstrated RNA's intrinsic ability to catalyze and regulate chemical reactions ${ }^{3-9}$. It is generally accepted that the transition from rich prebiotic chemistry to the earliest lifeforms must have included simpler compartments and protocells as intermediates to highly evolved compartmentalized systems consisting of genetic and catalytic polymers. Several lipid and fatty acid-containing membrane systems have been shown to facilitate compartmentalization ${ }^{10,11}$ and support templatedirected polymerization of $\mathrm{RNA}^{12}$. However, permeability and transport in lipid-based vesicles is highly sensitive to the size of molecules, and especially unfavorable as the cargo becomes charged and larger ${ }^{13}$.

Liquid-liquid phase-separated (LLPS) systems have been hypothesized as model prebiotic compartments ${ }^{14-16}$ because of their ability to assemble spontaneously from a variety of oligomeric or polymeric components and to encapsulate otherwise dilute solutes, enabling local concentrations of potentially functional molecules such as nucleic acids at many orders of magnitude higher than is present in the overall solution ${ }^{17}$. LLPS also allows diffusion both within and between the compartment and the surrounding environment, even for large and charged molecules such as RNAs ${ }^{18,19}$. Complex coacervates, which arise from phase separation of oppositely charged polyions, have been hypothesized as model protocells, or alternate biophysical compartments for prebiotic reactions ${ }^{15,20,21}$. Membraneless compartments such as the nucleolus and RNP granules exist in modern cells and have their own biological functions ${ }^{22-24}$. Formation of these RNA and protein-rich intracellular liquid phases relies on not only charge-charge interactions, but also $\pi-\pi$ stacking, $\mathrm{H}$ bonding, cation- $\pi$, and dipole-dipole contacts ${ }^{25}$. It is possible that biological membraneless organelles may have arisen as simple abiogenic phase-separated systems such as complex coacervates.

The highly charged nature of RNA suggests that it could have participated in formation of complex coacervates with polycations on early-Earth, thus providing primitive compartments for functional RNAs such as ribozymes and RNA aptamers. Polycations such as polyamines have been shown to condense nucleic acids and form complex coacervates with nucleotides, RNA, and other anionic polymers ${ }^{18,26,27}$. High concentrations of nucleotides have been reported for coacervates containing polylysine and ATP ${ }^{16}$. Similarly, coacervates of poly(allylamine) (PAH) and ATP strongly concentrate RNA molecules, nucleotides, and $\mathrm{Mg}^{2+}$ ions ${ }^{17}$. Compartmentalization in aqueous two-phase systems consisting of the uncharged polymers polyethylene glycol (PEG) and dextran has been shown to enhance ribozyme catalysis due to increased local concentration ${ }^{28}$. However, RNA functions in complex coacervates, which have quite different composition and properties than aqueous two-phase systems, are largely unexplored. Importantly, RNA partitioning within complex coacervates generally involves ion-pairing interactions with polycationic components ${ }^{17,18}$, which may inhibit necessary RNA functions by disrupting native RNA structures. In fact, certain biological membraneless compartments have been shown to destabilize RNA duplexes ${ }^{29}$. The hammerhead ribozyme has recently been shown to retain some activity inside polylysine/ carboxymethyldextran complex coacervates, with rates 60 -fold slower than in the absence of coacervates ${ }^{30}$.

In this report, we study the effect of coacervate composition on template-directed polymerization of RNA, and explored RNA aptamer and ribozyme activities within membraneless compartments formed by complex coacervates. We show that the identity of cationic polymers in the coacervates significantly affects template-directed polymerization of RNA molecules. We first demonstrate that coacervates made with specific polyamines can inhibit template-directed RNA polymerization, while some enhance the reaction at sub-optimal $\mathrm{Mg}^{2+}$ levels. The polyamines used in this study have varying charge-densities and propensity to interact with nucleic acids. Poly(allylamine) (PAH-260) has a high charge density with $\sim 17$ charges per $\mathrm{kDa}$ (see Reagents and synthesis in Methods), whereas oligoarginine $\left(R_{10}\right)$, polydiallyldimethylammonium chloride (PDAC-53), and oligolysine $\left(\mathrm{K}_{10}\right)$ have much lower charge densities at $~ 6.2,5.2$, and 6.3 charges per $\mathrm{kDa}$, respectively. We show that fluorescent RNA aptamers remain bright inside coacervates, thus maintaining their native fold. Finally, we demonstrate that RNA-cleavage reactions catalyzed by multiple ribozymes and a DNAzyme are enhanced in the presence of coacervates. Thus, depending on their chemical composition, complex coacervates could have not only supported RNA copying and RNA aptamer-ligand binding, but also enhanced ribozyme activity on early-Earth while efficiently compartmentalizing RNA and other biomolecules from bulk solutions.

\section{Results}

Impact of polyamines on template-directed RNA polymerization. We first sought to understand how the chemical identity of polyamines that form complex coacervates affects templatedirected polymerization of RNA with activated nucleotides (Fig. 1a). We carried out template-directed primer extension reactions at $\mathrm{pH} 8.0$ in the presence of different polyamines (Fig. 1b) that are largely protonated at this $\mathrm{pH}$. To study the effect of polyamines themselves, we performed the reactions in the absence of other polyions besides the RNA primer-template complex (i.e., no other polyanions to induce coacervation). Template-directed polymerization of RNA was assessed by the electrophoretic mobility shifts $(+1,+2$, and +3 etc.) arising from incorporation of nucleotides (Fig. 1c). We saw significant inhibition in the total amount of product formed by primer extension after $5 \mathrm{~h}$ in the presence of $\geq 500 \mu \mathrm{M}$ total positive charge from PAH-260 (Fig. 1c). Similarly, oligoarginine $\left(R_{10}\right)$ also showed inhibition at $\geq 500 \mu \mathrm{M}$ total positive charge, with product yield reduced by more than half compared to reactions in the absence of any cationic polymers. Although $\mathrm{R}_{10}$ has lower charge density than PAH-260 ( 6.2 vs 17 charge/ $\mathrm{kDa}$ ), the level of inhibition is similar for these polycations. Recently, 10-mer oligoarginine was reported to inhibit ribozyme-catalyzed RNA polymerization at $10 \mu \mathrm{M}^{31}$; suggesting that inhibition of RNA chemistries by oligoarginine may be a prevalent phenomenon. Ribozyme-catalyzed RNA polymerization has been reported to be enhanced in the presence of 10-mer oligolysine and other heteropeptides derived from the ribosomal core proteins ${ }^{31}$; however, we did not observe any significant enhancement or inhibition of template-directed polymerization of RNA in the presence of a 10-mer oligolysine $\left(\mathrm{K}_{10}\right)$, which has a charge density of 6.3 charge/ $\mathrm{kDa}$. Templatedirected polymerization was however inhibited by larger 100-mer polylysine $\left(\mathrm{K}_{100}\right)$, as well as protamine, which is a natural arginine-rich protein $(\sim 5$ charge/ $/ \mathrm{kDa})$ (Supplementary Figure 1a, $\mathrm{b}$ left). These findings suggest that charge density may not be the primary driver in inhibition of template-directed polymerization.

To further characterize the role of polyamines in inhibition of template-directed polymerization, we tested the effects of polyallyldiammonium chloride (PDAC), a quaternary amine that has been reported to form weaker/more labile ion-pairing interactions as compared to $\mathrm{PAH}^{26}$. We reasoned that weaker interactions between the polycationic component and the polyanionic RNA primer-template complex due to buried positive charge may reduce interference with template-directed 
a

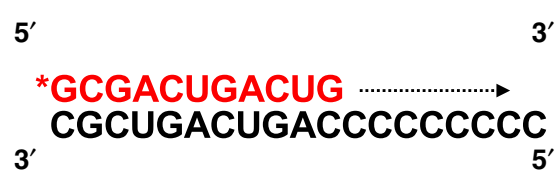

b

Poly(allyl)amine (PAH-260)<smiles>CCC(CC(C)(CC)CC)C(C)C</smiles>

Oligoarginine $\left(\mathbf{R}_{10}\right)$<smiles></smiles><smiles>Cc1nccn1P(=O)([O-])OCC1OC(n2cnc3c(=O)[nH]c(N)nc32)C(O)C1O</smiles>

(⿸丆口

C

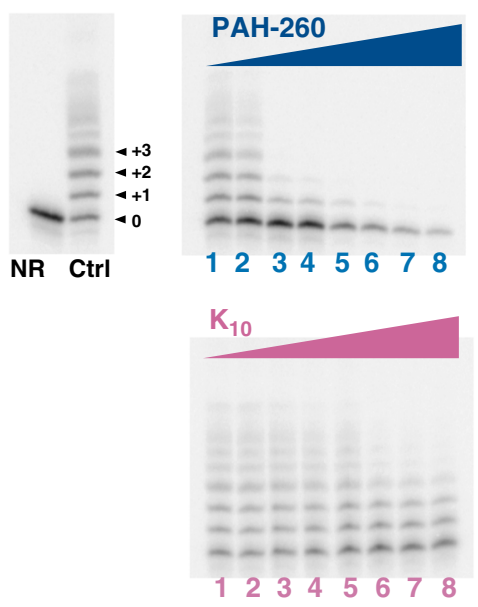

Oligolysine $\left(\mathrm{K}_{10}\right)$<smiles>CC(C)(C)NC(CCCC[NH3+])C(=O)C1(C#N)CO1</smiles>

Polydiallyldimethyl-ammonium(PDAC)<smiles>CCCCCCCCCCCCC(C)(C)C</smiles>

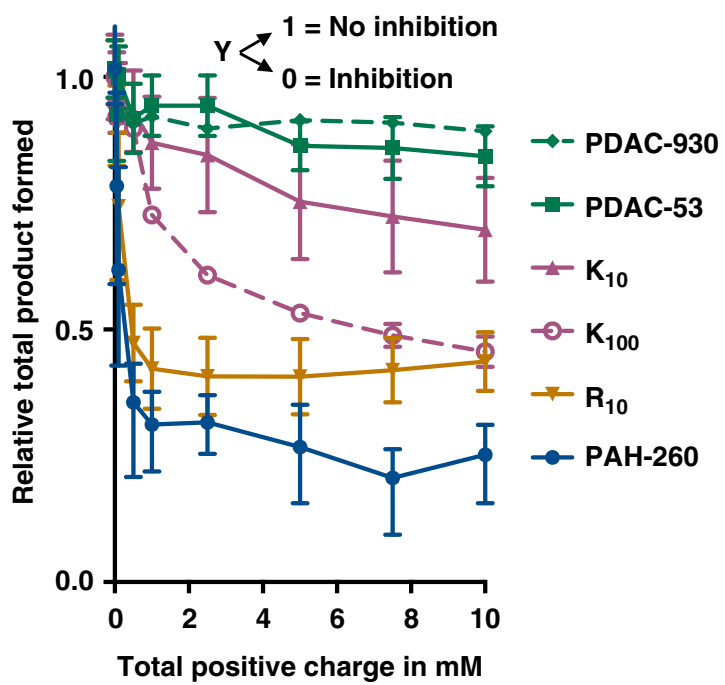

Fig. 1 Effect of polyamines on template-directed polymerization. a Primer (red)-template (black) complex used for template-directed polymerization using guanosine 5'-(phosphor)-2-methylimidazolide (2-Me-ImpG). b Structures of polyamines used. c Representative denaturing polyacrylamide gel images show extension of ${ }^{32} \mathrm{P}$-labeled primer. Lane $\mathrm{Ctrl}$ indicates reaction without any cationic polymer and NR indicates no reaction in the absence of monomer, lanes $1-8$ contain $0.050,0.10,0.50,1.0,2.5,5.0,7.5$, and $10 \mathrm{mM}$ total positive charge from PAH-260 (blue), $\mathrm{R}_{10}$ (orange), $\mathrm{K}_{10}$ (dark pink), and PDAC-53

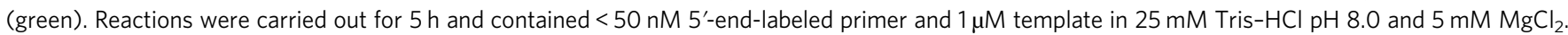
Fraction converted to product was normalized to the yield in the absence of any cation ctrl. Error bars represent S.E.M. from three independent experiments. Uncropped gel images are shown in Supplementary Figure 14a

polymerization. Strikingly, template-directed polymerization was maintained up to $10 \mathrm{mM}$ total positive charge of PDAC-53 (Fig. 1c). Furthermore, the reaction was unaffected in the presence of PDAC with 230 monomers (PDAC-930) (Supplementary Figure $1 \mathrm{~b}$, right). These results suggest that inhibition of template-directed polymerization by polyamines may thus be alleviated in cases where the amines are conformationally locked and the positive charge resulting from the protonation of nitrogens is shielded by other functional groups, preventing strong and interfering interactions with the nucleic acid. The difference in inhibition between $K_{10}$ and $K_{100}$ may be due to increased multivalency and flexibility of $K_{100}$ compared to $K_{10}$. No significant difference was seen in the amount of $2-\mathrm{Me}-\mathrm{ImpG}$ remaining after $5 \mathrm{~h}$ of incubation in the presence of different polycations, suggesting that the observed inhibition was not due to polyamines reacting with 2-Me-ImpG (Supplementary
Figure 1c). These results are in line with previous observations where only about $12 \%$ of $2-\mathrm{Me}$-ImpG degraded in the presence of spermine in 18 days at $\mathrm{pH} 7.0^{32}$. Microscopy images revealed that at $1 \mathrm{mM}$ total charge concentration, $\mathrm{PAH}$ and $\mathrm{R}_{10}$ are able to form phase-separated droplets with $10 \mathrm{mM}$ 2-Me-ImpG even in the absence of longer polyanions (Supplementary Figure 2). These data are consistent with the greater propensity of these polyamines for ion-pairing interactions, not only with the primer/template complex, but even with nucleotide monomers. To study the effect of coacervation, we focused our attention to PDAC-53 and $\mathrm{K}_{10}$, which did not form any detectable droplets with the nucleotide monomer.

PDAC coacervates support template-directed polymerization. We next explored the suitability of different coacervates for template-directed RNA polymerization. An 11-mer polyA RNA 
molecule $\left(\mathrm{rA}_{11}\right)$ was used as the polyanion to drive phase separation of PDAC-53, $\mathrm{K}_{10}$, or $\mathrm{R}_{10}$ at $10 \mathrm{mM}, 1: 1$ charge balance (Supplementary Figure 3a, top panels). Fluorescently labeled RNA primer pre-annealed to the template was used to verify selective RNA partitioning inside the coacervate phase (Supplementary Figure $3 \mathrm{a}$, bottom panels). To evaluate the concentrations of RNA primer inside the coacervate phase, fluorescence in the droplets was compared to a standard curve made in buffer (Supplementary Figure $3 \mathrm{~b}$ ). When just $0.5 \mu \mathrm{M}$ of the primer complexed with $0.75 \mu \mathrm{M}$ template was added to the bulk, the concentrations of primer inside coacervate phases were calculated to be around $78 \pm 6,30 \pm 1$, and $56 \pm 12 \mu \mathrm{M}$ for PDAC-53, $\mathrm{K}_{10}$, and $\mathrm{R}_{10}$ coacervates, respectively, indicating that all three coacervate systems strongly partition RNA inside the condensed phase.

Next, we compared template-directed polymerization of RNA in the presence of coacervates made using PDAC-53, $\mathrm{K}_{10}$, or $\mathrm{R}_{10}$ as the polycation and $\mathrm{rA}_{11}$ as the polyanion. $10 \mathrm{mM}$ total positive charge from each of the cationic polymers and $7.5 \mathrm{mM}$ total negative charge from $\mathrm{rA}_{11}$ was used to drive coacervation. This charge imbalance was chosen to facilitate coacervate uptake of 2Me-ImpG, which has one negative charge at reaction conditions. The fraction of primer converted to polymerized products by template-directed polymerization in PDAC-53/rA 11 and $\mathrm{K}_{10}$ $/ \mathrm{rA}_{11}$ coacervates were similar to buffer at about $50 \%$ after $5 \mathrm{~h}$, but yields were lower for $\mathrm{R}_{10} / \mathrm{rA}_{11}$ coacervates, at about $30 \%$ after $5 \mathrm{~h}$ (Fig. 2a). Microscopy experiments revealed that PDAC-53/ $\mathrm{rA}_{11}$ coacervates remain stable over the time course of templatedirected polymerization of RNA (Supplementary Figure 4a).

To demonstrate that the template-directed polymerization reaction occurs inside complex coacervates and not the dilute phase, we centrifuged the reactions and separated the bulk supernatant and the condensed phase. Reactions were allowed to proceed independently in the separated phases. Quantification of radiolabeled signal from the gel image for both coacervates and supernatant revealed that $>90 \%$ of the primer partitioned to the condensed phase for PDAC-53 and $\mathrm{R}_{10}$ coacervates, while $\sim 85 \%$ and $\sim 65 \%$ of the RNA remained in the condensed phase for $\mathrm{PAH}-260$ and $\mathrm{K}_{10}$, respectively (Supplementary Figure $4 \mathrm{~b}$ ). Furthermore, higher bands $(\mathrm{N}+2$ and $\mathrm{N}+3)$ were observed only for coacervates containing PDAC-53 and $\mathrm{rA}_{11}$ indicating significant template-directed RNA polymerization (Fig. 2b). These data show that among the coacervate compositions tested, only the PDAC-53/ $\mathrm{rA}_{11}$ coacervates are suitable to yield longer RNA polymers from template-directed RNA polymerization. It should be noted that we observed addition of up to two nucleotides in the supernatant phase of $\mathrm{R}_{10} / \mathrm{rA}_{11}$ coacervates, suggesting that polymerized bands in Fig. $2 \mathrm{a}$ for this condition is likely from the reaction in the dilute phase. And finally, to test whether polyanion identity had any major effect on templatedirected polymerization, we performed template-directed polymerization under coacervation conditions using oligoaspartic acid $\left(D_{10}\right)$ with different polycations. Oligoaspartic acid was chosen because Asp is considered one of the early amino acids ${ }^{33}$. Product yields after $1.5 \mathrm{~h}$ were similar for reactions performed in buffer, and in $\mathrm{PDAC} / \mathrm{rA}_{11}, \mathrm{PDAC} / \mathrm{D}_{10}$, and $\mathrm{K}_{10} / \mathrm{D}_{10}$ coacervates (Supplementary Figure 4c, 27-22\%). However, the product yield was significantly reduced for $\mathrm{R}_{10} / \mathrm{D}_{10}$ coacervates $(7.5 \%)$. These data suggest that oligopeptides can also serve the role of polyanion to form coacervates while supporting templatedirected polymerization.

To better understand the differences between the specific coacervates, we performed fluorescence recovery after photobleaching (FRAP) experiments, which can report on physical properties of molecules inside biogenic and abiogenic membraneless compartments ${ }^{18,19,34}$. FRAP of a Cy3-labeled RNA primer
(Fig. 2c) revealed significantly faster fluorescence recovery in PDAC-53/rA $\mathrm{A}_{11}$ as compared to $\mathrm{R}_{10} / \mathrm{rA}_{11}$ coacervates. Half-times for fluorescence recovery $\left(t_{1 / 2}\right)$ were $27 \pm 3 \mathrm{~s}$ for $\mathrm{PDAC} / \mathrm{rA}_{11}$ coacervates and $101 \pm 6 \mathrm{~s}$ for $\mathrm{R}_{10} / \mathrm{rA}_{11}$ coacervates. Structural analyses have shown that arginine dominates as the most frequent amino acid at the binding interface of RNA aptamers and their protein targets ${ }^{35}$, presumably due to its ability to interact with nucleic acids via multiple mechanisms. Strong arginine-RNA interactions could also explain slower RNA diffusion within this condensed phase and poor RNA polymerization (see above). FRAP experiments where coacervates contained Cy3-labeled RNA primer complexed with the template showed a similar trend, with the half-times for fluorescence recovery $\left(t_{1 / 2}\right)$ of $49 \pm 5 \mathrm{~s}$ and $250 \pm 64 \mathrm{~s}$ for PDAC-53/rA 11 and $\mathrm{R}_{10} / \mathrm{rA}_{11}$ coacervates, respectively (Supplementary Figure 5a). Overall, the apparent diffusion coefficients were fourfold to fivefold higher for PDAC-53/rA $\mathrm{A}_{11}$ compared to $\mathrm{R}_{10} / \mathrm{rA}_{11}$ coacervates, regardless of whether the RNA primer was singlestranded or part of the duplex with the template (Supplementary Figure 5b).

Polyamines rescue polymerization at sub-optimal magnesium levels. We previously reported high $\mathrm{Mg}^{2+}$ concentration inside $\mathrm{PAH} / \mathrm{ATP}$ coacervates ${ }^{17}$. To test whether $\mathrm{PDAC} / \mathrm{rA}_{11}$ coacervates also concentrate $\mathrm{Mg}^{2+}$, we measured $\mathrm{Mg}^{2+}$ levels inside the condensed phase using Atomic Absorption Spectroscopy (AAS). We estimated the volumes of $\mathrm{PDAC} / \mathrm{rA}_{11}$ coacervates by centrifuging the bulk coacervate solution and comparing to standards, where $20 \mu \mathrm{L}$ of bulk solution gave about $1 \mu \mathrm{L}$ coacervate phase (Supplementary Figure 6a). To calculate the $\mathrm{Mg}^{2+}$ levels, coacervate solutions with $5 \mathrm{mM}$ total $\mathrm{Mg}^{2+}$ were prepared. Samples were centrifuged and the $\mathrm{Mg}^{2+}$ remaining in the supernatant was measured (Supplementary Figure 6b). About $\sim 27 \%$ of the total $\mathrm{Mg}^{2+}$ is localized to the coacervate phase for $\mathrm{PDAC} / \mathrm{rA}_{11}$ system. Based on estimated $1 \mu \mathrm{L}$ coacervate volume, this corresponds to $26 \pm 3 \mathrm{mM} \mathrm{Mg}^{2+}$ (Fig. 3a).

To determine whether coacervation by $\mathrm{PDAC} / \mathrm{rA}_{11}$ would facilitate template-directed polymerization of RNA at suboptimal total magnesium concentration, we performed the reactions at different amounts of $\mathrm{Mg}^{2+}$ (Fig. 3b). Above $1 \mathrm{mM}$ $\mathrm{Mg}^{2+}$, no gain in product yield under coacervation compared to buffer conditions was evident. However, in the presence of only $0.5 \mathrm{mM} \mathrm{Mg}^{2+}$, an increase in product yield in coacervate solutions over buffer was observed. It should be noted that while we estimate roughly $26 \mathrm{mM} \mathrm{Mg}^{2+}$ in the coacervates, the yields of polymerization in $5.0 \mathrm{mM}$ added $\mathrm{Mg}^{2+}$ are not commensurate with a fivefold increase in $\mathrm{Mg}^{2+}$, suggesting that $\mathrm{Mg}^{2+}$ concentration alone is not sufficient to enhance templatedirected polymerization in coacervates. To our surprise, we saw significant product formation even when magnesium was completely omitted from the buffer (Fig. 3b, c). These data indicate that the positive charge in PDAC may actively participate in chemistry in the absence of metal ions.

To further investigate this possibility, we performed templatedirected reactions in 0 and $1 \mathrm{mM}$ added $\mathrm{MgCl}_{2}$ in the absence of $\mathrm{rA}_{11}$, i.e., no polyanion for coacervation (Fig. 3d). In this experiment, $5 \mathrm{mM}$ EDTA was added to chelate background divalents that may contribute to catalysis. Addition of EDTA essentially halted the slow reaction in the absence of added $\mathrm{Mg}^{2+}$ (Fig. 3d, lane 3), suggesting that EDTA served to sequester trace divalent ions. Surprisingly, in the presence of $5 \mathrm{mM}$ EDTA and no added $\mathrm{Mg}^{2+}$, the yield of template-directed polymerization was enhanced eightfold by PDAC-53 (Fig. 3d, lane 5 and Supplementary Figure 7a). Addition of $5 \mathrm{mM}$ EDTA stopped the polymerization reaction in $1 \mathrm{mM} \mathrm{Mg}^{2+}(27 \%$ vs $4 \%$ yield $)$, 
a

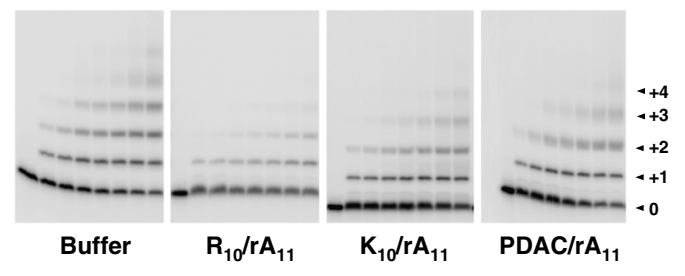

b

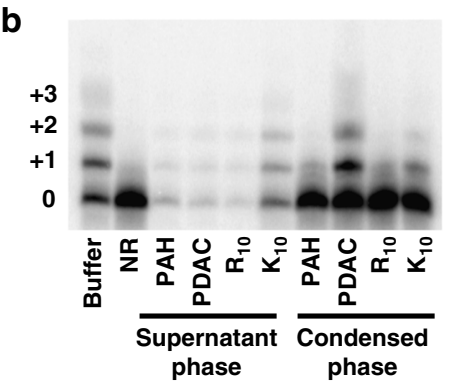

C

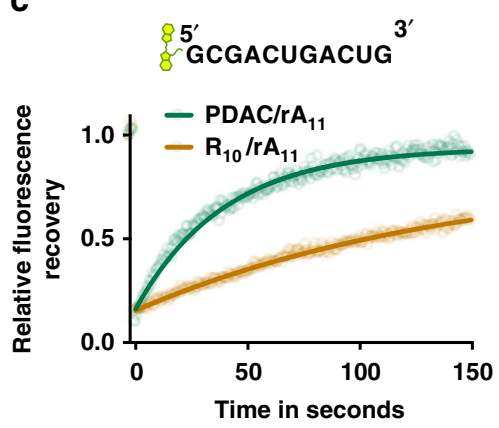

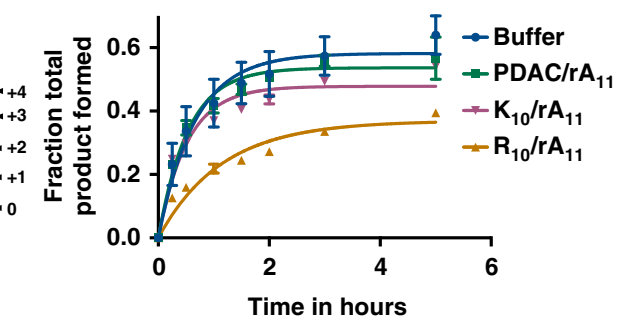
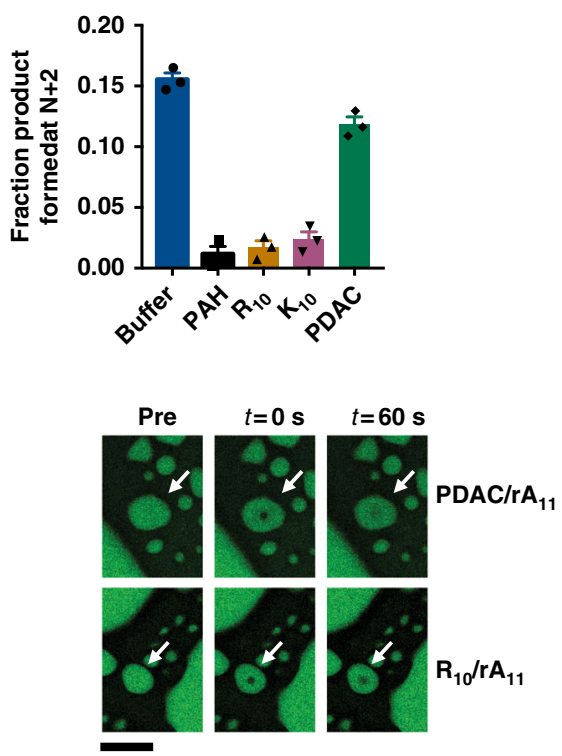

Fig. 2 Coacervates of PDAC/rA 11 RNA support template-directed polymerization. a Template-directed polymerization reactions in the presence of coacervates. Coacervates were formed by adding respective polycations (10 mM total positive charge) to solutions containing $10 \mathrm{mM} 2$-me-ImpG and $7.5 \mathrm{mM}$ total negative charge from $\mathrm{rA}_{11}$ in $5 \mathrm{mM} \mathrm{Mg}$ and $25 \mathrm{mM}$ Tris- $\mathrm{HCl} \mathrm{pH} \mathrm{8.0.} \mathrm{Reactions} \mathrm{were} \mathrm{initiated} \mathrm{by} \mathrm{adding} \mathrm{pre-annealed} 5^{\prime}$-end-labeled RNA primer and unlabeled template, and incubated at room temperature and time points were taken at $0 \mathrm{~min}, 15 \mathrm{~min}, 30 \mathrm{~min}, 1 \mathrm{~h}, 1.5 \mathrm{~h}, 2 \mathrm{~h}, 3 \mathrm{~h}$, and $5 \mathrm{~h}$. Samples were separated by denaturing PAGE. Total product formed was calculated by quantifying all the visible bands in the given lane. Data were fit to first order exponential. Error bars represent S.E.M from three independent experiments. b Reactions were initiated as a except the Mg concentration was decreased to $1 \mathrm{mM}$ to slow the reactions. Reactions were immediately centrifuged at $14,000 \times g$ after initiation. The bulk phase was then separated from the condensed phase and the two phases were allowed to react separately for $5 \mathrm{~h}$. Quantifications of product yields are shown for condensed phases. Error bars represent S.E.M. from three independent experiments. $c$ FRAP recovery curves for Cy3-labeled RNA primer in PDAC/rA 11 and $\mathrm{R}_{10} / \mathrm{rA} \mathrm{A}_{11}$ coacervates at $10 \mathrm{mM}$ chargebalanced condition. Shown as best fits to Eq. (2) (five independent trials). Representative images of PDAC/rA 11 (top) and $R_{10} / r A_{11}(b o t t o m$ ). Scale bar is $5 \mu \mathrm{m}$. Uncropped gel images are shown in Supplementary Figure 14b, c

which was restored by PDAC-53 to the same extent as in no added $\mathrm{Mg}^{2+}$, as expected (4\% vs 27\%) (Fig. 3d, lanes 7 and 9, and Supplementary Figure $7 \mathrm{a}$ ). Moreover, $1 \mathrm{mM}$ positive charge in PDAC-53 activates the reaction to the same extent as $1 \mathrm{mM}$ $\mathrm{Mg}^{2+}$ (Fig. 3d, lanes 8 and 9). Addition of $1 \mathrm{mM}$ EDTA to reactions containing $1 \mathrm{mM} \mathrm{MgCl} 2$ inhibited the polymerization, while it did not significantly affect reactions containing $5 \mathrm{mM}$ $\mathrm{MgCl}_{2}$ (Supplementary Figure $7 \mathrm{~b}$, lanes 2 and 3 vs 6 and 7 ), indicating that inhibition by EDTA is indeed due to $\mathrm{Mg}^{2+}$ sequestration and that EDTA itself does not inhibit the reaction. Furthermore, unlike PDAC-53 polymer, tetramethyammonium monomers did not rescue the polymerization in the presence of EDTA (Supplementary Figure 7c). These data suggest that enhancements in polymerization is likely from favorable contributions from the polyamine polymer.

Active RNA aptamer inside coacervates. Small molecule-binding aptamer function is highly relevant to origin of life, as metabolic ribozymes likely needed to form binding pockets to bind small metabolites. The broccoli aptamer, which is similar to Spinach aptamer ${ }^{36}$, uses a precise 3D RNA structure to bind to the dye 3,5-difluoro-4-hydroxybenzylidene imidazolinone (DFHBI) and activate its fluorescence ${ }^{37}$. In vitro transcription reactions of Spinach aptamer have been performed within spermidine/polyU complex coacervates ${ }^{38}$. We sought to understand whether, and how well, PDAC-53/rA11 coacervates could support RNA aptamer activity. When DFHBI was added alone to PDAC-53/rA 11 coacervates, no fluorescence was observed within the droplets, showing that coacervates alone do not induce fluorescence from DFHBI (Fig. 4a). Next, cotranscriptional fluorescence was measured for stabilized dimeric broccoli ${ }^{39}(\mathrm{sdB})$ aptamer and its inactive mutant to verify aptamer-induced fluorescence (Supplementary Figure $8 \mathrm{a}$ ). Purified $\mathrm{sdB}$ aptamer was complexed with the dye and added to PDAC-53/ $\mathrm{rA}_{11}$ coacervate-containing mixture. Fluorescent coacervate droplets indicated that the sdB aptamer remained natively folded inside coacervates (Fig. 4a). Importantly, no fluorescence was observed in coacervates with the G63C/G87C binding site mutant (equivalent $\mathrm{G}$ in each aptamer 


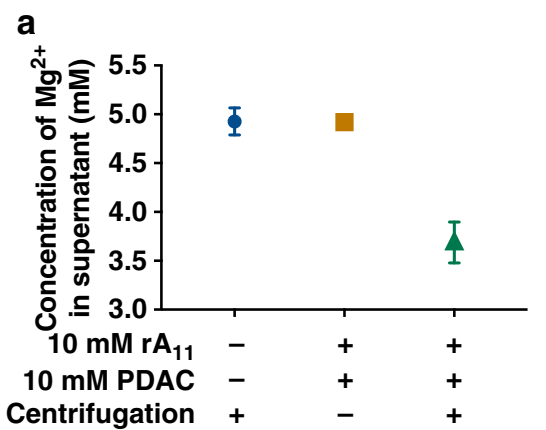

b
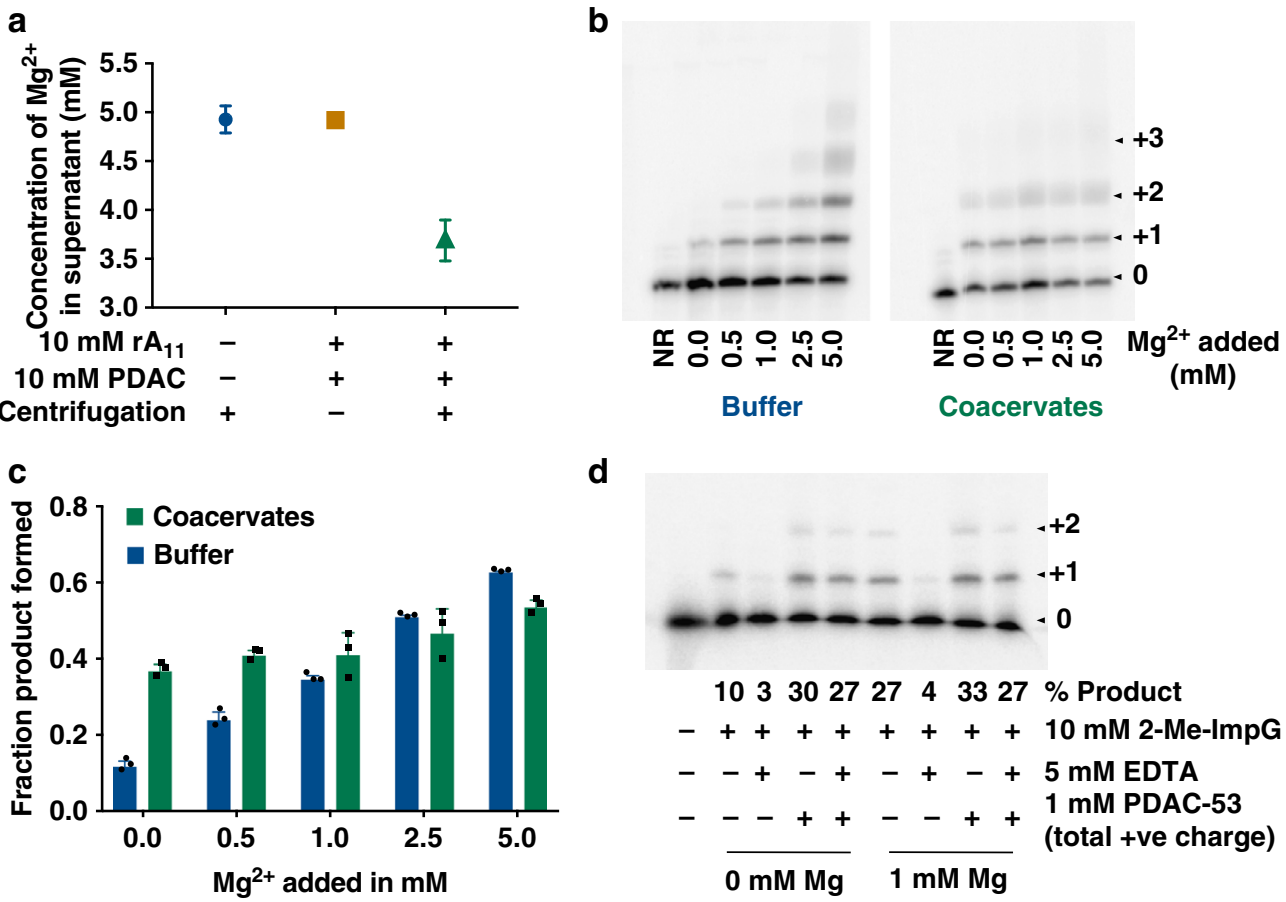

d

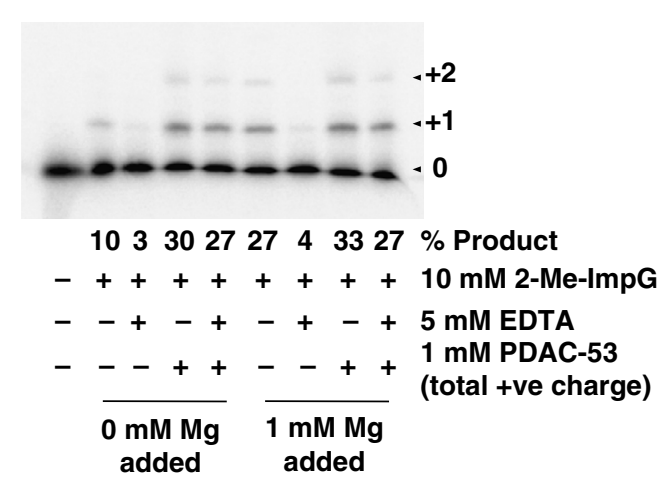

Fig. 3 Template-directed polymerization at sub-optimal $\mathrm{Mg}$ concentrations. a $\mathrm{Mg}{ }^{2+}$ levels were measured by atomic absorption spectroscopy. Solutions with $5 \mathrm{mM} \mathrm{MgCl} 2$ were formed in $25 \mathrm{mM}$ Tris- $\mathrm{HCl} \mathrm{pH} 8.0$ with indicated anions and cations, followed by centrifugation at $14,000 \times g$ for 2 min. A portion of the supernatant phase was removed and diluted in water prior to measurement. Error bars represent the range of values from two experiments. $\mathbf{b}$ Yields of template-directed polymerization at different amounts of added $\mathrm{Mg}$ in presence and absence of PDAC-53/rA $\mathrm{A}_{11}$ coacervates. $\mathbf{c}$ Quantifications from $\mathbf{b}$. Error bars represent S.E.M. from three independent experiments. $\mathbf{d}$ Template-directed polymerization reactions were assembled as previously described in the presence or absence of indicated molecules and ions. Uncropped gel images are shown in Supplementary Figure 15a, b

domain) (Fig. 4a and Supplementary Figure 8a) ${ }^{37}$. Additionally, the droplets were fluorescent when the RNA was allowed to diffuse into coacervates already containing ligand or when the ligand was allowed to diffuse into coacervates already containing the RNA (Supplementary Figure 8b). These data indicate that appropriate small molecules and RNAs can be readily taken up by the coacervates and remain natively folded. Similar fluorescence intensities were measured when sdB aptamer-DFHBI complex was in buffer as compared to PDAC-53/rA11 coacervates, while the fluorescence remained close to background in the absence of the RNA aptamer in buffer and in coacervates (Fig. 4b). These data suggest that the fraction of RNA aptamer that is folded to a functional form is similar in coacervates as in buffer.

Coacervates enhance ribozyme activity. After studying RNA polymerization and RNA aptamer function, we explored whether PDAC-53/ $\mathrm{rA}_{11}$ coacervates provide suitable reaction conditions for ribozyme catalysis. We evaluated full-length hammerhead ribozyme (HHRz) cleavage reactions (Fig. 5a) in coacervate phases (separated from supernatant phases) of either PDAC-53/ $\mathrm{rA}_{11}$ or $\mathrm{R}_{10} / \mathrm{rA}_{11}$ coacervates. The fraction cleaved was relatively smaller for both PDAC/ $\mathrm{rA}_{11}$ and $\mathrm{R}_{10} / \mathrm{rA}_{11}$ coacervates compared to buffer after $1 \mathrm{~h}$. At $1 \mathrm{mM} \mathrm{Mg}^{2+}$, yields were $66 \%, 31 \%$, and $11 \%$ for buffer, $\mathrm{PDAC} / \mathrm{rA}_{11}$, and $\mathrm{R}_{10} / \mathrm{rA}_{11}$ coacervates, respectively. The yields were considerably higher ( 3 -fold) for PDAC$53 / \mathrm{rA}_{11}$ coacervates compared to $\mathrm{R}_{10}$. As expected, almost no signal was observed in the supernatant phase after partitioning of coacervate phase (Supplementary Figure 9a). These data suggest that PDAC-53/ $\mathrm{rA}_{11}$ coacervates support not only templatedirected RNA polymerization, but also catalytic RNA functions.

Next, we asked whether coacervates could actually enhance ribozyme activity. Enhanced activity of the hammerhead ribozyme has been previously reported in aqueous two-phase systems (ATPS) of PEG and dextran by our labs ${ }^{28}$. We sought to understand whether concentration of biomolecules by coacervation can also lead to enhancements in ribozyme reactions at low enzyme concentrations. To explore this possibility, we measured the apparent dissociation constant $\left(K_{\mathrm{D}}\right)$ between the ribozyme and the substrate to be $220 \pm 10 \mathrm{nM}$ at $1 \mathrm{mM} \mathrm{MgCl}_{2}$ and $28 \pm$ $3 \mathrm{nM}$ at $25 \mathrm{mM} \mathrm{MgCl} 2$ in the background of $2.5 \mathrm{mM} \mathrm{KCl}$ (Supplementary Figure 9b). We then estimated the ribozyme concentration inside PDAC-53 and oligoaspartic acid $\left(\mathrm{D}_{10}\right)$ coacervates by using hammerhead ribozyme with a fluorescent tag, and comparing the fluorescence inside coacervates to standards. PDAC-53/D 10 coacervates indeed concentrated the ribozyme, where the concentration of enzyme strand inside the coacervate was measured to be $45 \pm 3,110 \pm 5$, and $140 \pm 9 \mu \mathrm{M}$ when only 10,25 , and $50 \mathrm{nM}$ of fluorescently labeled ribozyme was added to the bulk coacervates, respectively (Supplementary Figure 10).

To investigate whether this ribozyme accumulation in coacervates could enhance catalysis, we performed hammerhead cleavage reactions in the presence of PDAC- $53 / \mathrm{D}_{10}$ coacervates. When concentrations of the enzyme strand were reduced to $1 \mathrm{nM}$ and $5 \mathrm{nM}$ in $1 \mathrm{mM} \mathrm{Mg}{ }^{2+}$, i.e., below bulk $K_{\mathrm{D}}$ to remain under $k_{\text {cat }} / K_{\mathrm{M}}$ conditions, ribozyme cleavage was significantly reduced with only maximal cleavage of $4-6 \%$ (Fig. 5c). Surprisingly, even at these concentrations, $33-45 \%$ cleaved product was observed when the reaction was performed in the presence of PDAC/D 10 coacervates. In other words, reactions performed in buffer alone gave $5-10 \times$ less product at any given point in time. Importantly, reactions performed in the presence of either PDAC-53 or $\mathrm{D}_{10}$ alone did not enhance the ribozyme activity (Supplementary Figure 11), demonstrating that the mechanism of enhancement is 
a

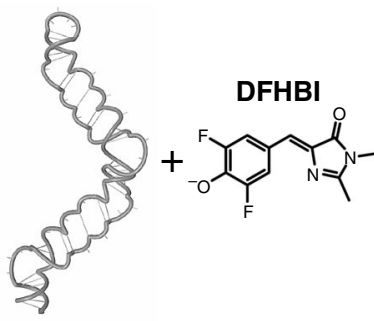

Non-fluorescent
aptamer

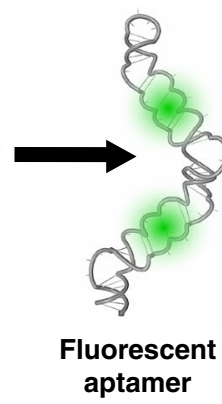

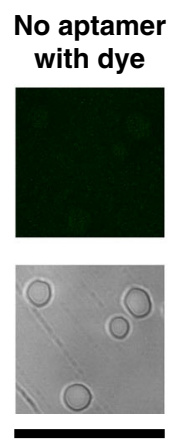

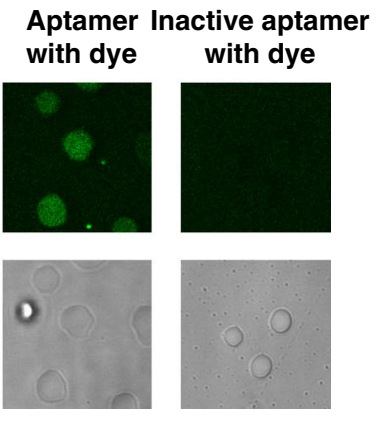

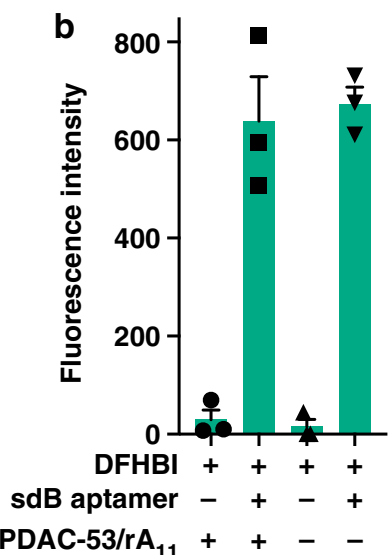

Fig. 4 Active RNA aptamer folding inside PDAC/rA 11 coacervates. a (Left) Model of stabilized dimeric broccoli (sdB) RNA drawn in NUPACK55, and confocal microscopy images (right) of PDAC-53/rA 11 coacervates containing sdB RNA complexed with DFHBI dye. No fluorescence is seen when coacervates contain only DFHBI dye or an inactive mutant of the aptamer. Coacervates contained $100 \mathrm{nM}$ sdB RNA and $10 \mu \mathrm{M}$ DFHBI in $25 \mathrm{mM}$ Tris pH $8.0,5 \mathrm{mM} \mathrm{MgCl}_{2}$ and $5 \mathrm{mM} \mathrm{KCl}$. $488 \mathrm{~nm}$ laser was used for excitation and emission window was $500-550 \mathrm{~nm}$. Scale bar is $20 \mu \mathrm{m}$. b Bulk fluorescence

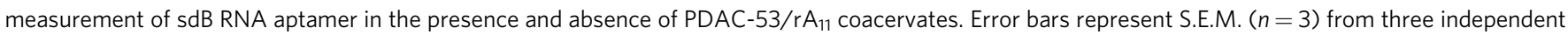
experiments

due to coacervation. Finally, to test whether the enhancement of ribozyme reaction is polycation-specific, we performed the reaction in the presence of coacervates containing PDAC, $\mathrm{K}_{10}$, or $\mathrm{R}_{10}$ as polycations and $\mathrm{D}_{10}$ as the polyanion. Under low enzyme concentration, both PDAC- and $\mathrm{K}_{10}$-containing coacervates showed greatly enhanced product yield compared to buffer (Fig. 5d) while the product yields in the presence of $\mathrm{R}_{10^{-}}$ containing coacervates were relatively low. Taken together, these data indicate that complex coacervates can not only support RNA catalysis as previously described ${ }^{30}$, but also provide a microenvironment that enhances RNA catalysis when RNA is scarce by concentrating RNA molecules.

Activation of multi-domain split ribozyme by coacervates. Another potential mechanism for reaction activation by coacervates is their ability to concentrate small molecules, which can serve as cofactors in catalysis ${ }^{17,18}$. To evaluate this possibility, we investigated the multi-domain split hairpin ribozyme ${ }^{40}$ reaction which is stimulated by spermine at low magnesium concentrations ${ }^{41}$ (Fig. 6a). In the multi-domain split Hairpin ribozyme, the complex of substrate (blue) and the substrate-binding strand (black) form the "loop A" of the ribozyme system. The "loop B" is formed by a separate enzyme strand (green). We first validated previously reported ${ }^{40}$ cleavage activity of the multi-domain split hairpin ribozyme in $25 \mathrm{mM} \mathrm{MgCl}_{2}$ and $25 \mathrm{mM} \mathrm{KCl}$ at $\mathrm{pH} 7.5$, and under saturating concentrations of the enzyme and the substrate-binding strands in the absence of coacervates. Under these conditions, cleavage of substrate was readily observed (Fig. 6a, gel image and 6b, blue trace). When the loop B and the substrate-binding strands were reduced to $25 \mathrm{nM}$ and $50 \mathrm{nM}$, respectively, in buffer containing $2.5 \mathrm{mM} \mathrm{MgCl} 2$ and $2.5 \mathrm{mM}$ $\mathrm{KCl}$, no detectable product was observed (Fig. $6 \mathrm{~b}$, left image and orange trace). A slight increase in product yield was observed when spermine ( $5 \mathrm{mM}$ total positive charge) was added to the reaction, in the absence of coacervates (Fig. $6 \mathrm{~b}$, middle image and green trace), but the overall yields were significantly lower compared to saturating concentrations of loop A and loop B. We then performed the reaction in a hybrid coacervate system of PDAC53 and spermine as polycations with polyaspartic acid, $\mathrm{D}_{30}$, as the polyanion. Surprisingly, under these conditions, the ribozyme cleavage was significantly enhanced compared to reactions in low $\mathrm{Mg}^{2+}$ and $\mathrm{K}^{+}$without coacervates (Fig. 6b, right image and black trace). Importantly, when only PDAC-53 and $\mathrm{D}_{30}$ are present no enhancement in ribozyme activity is observed (Supplementary Figure $12 \mathrm{~b}$ ) despite the presence of coacervates. On a similar note, when spermine and $\mathrm{D}_{30}$ are present in the reaction, no enhancement is observed, and under these conditions no coacervates are present (Supplementary Figure 12c). Taken together, these data indicate that complex coacervates can also enhance ribozyme catalysis by encapsulating cofactors that stimulate the reactions.

Coacervate-mediated enhancement of a DNAzyme. As coacervate-dependent enhancement is primarily due to concentration effect, we sought to understand whether it can be applied to other catalytic systems besides RNA enzymes. The 10-23 deoxyribonucleic acid enzyme (DNAzyme) was selected to cleave RNA molecules by in vitro evolution ${ }^{42}$. At $2.5 \mathrm{mM} \mathrm{MgCl}_{2}$ and saturating concentrations of the DNAzyme, we observed efficient cleavage of the substrate, with about $65 \%$ yield after $1.5 \mathrm{~h}$ (Fig. 7a). However, when the enzyme concentration was reduced to $5 \mathrm{nM}$, the cleavage reaction of the substrate was significantly reduced ( $10 \%$ yield after $2 \mathrm{~h}$ ) (Fig. $7 \mathrm{~b}$, top gel and solid orange trace). In the presence of coacervates, the reaction was partially restored, with fourfold improvement in product yield compared to reactions in buffer alone after $2 \mathrm{~h}(\sim 40 \%$ vs $\sim 10 \%)$ (Fig. $7 \mathrm{~b})$. Similar coacervation-induced stimulation was observed when the reactions were performed at $5 \mathrm{mM} \mathrm{Mg}^{2+}$ (Fig. $7 \mathrm{~b}$, dashed traces and Supplementary Figure 13a). Identical electrophoretic mobility shifts of the cleaved products from different reaction conditions support the same cleavage site for all the conditions (Supplementary Figure 13b). Taken together, these data indicate that coacervate-mediated enhancements under sub-optimal conditions is not limited to RNA enzymes.

\section{Discussion}

In this study, we have combined model prebiotic compartmentalization systems of coacervates and essential RNA functions of template-directed RNA polymerization, RNA aptamer-ligand interactions, and ribozyme catalysis. Inhibition of polymerization by PAH-260, $R_{10}$, and $K_{100}$ in the absence of counterions suggests that the highly charged polyamine alone is capable of interfering with template-directed RNA polymerization. It is likely that the extensive charge-charge interactions and $\mathrm{H}$-bonding disrupt the 
a

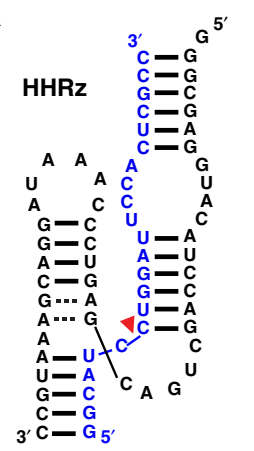

b

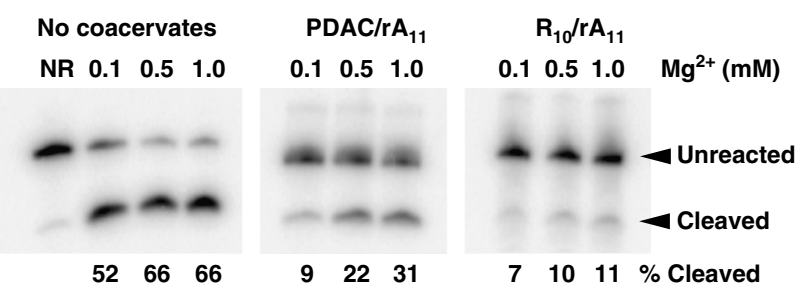

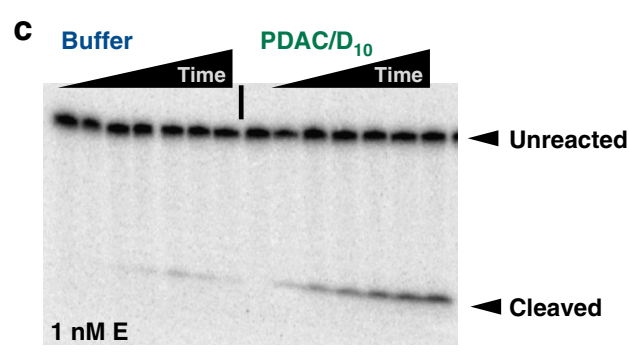
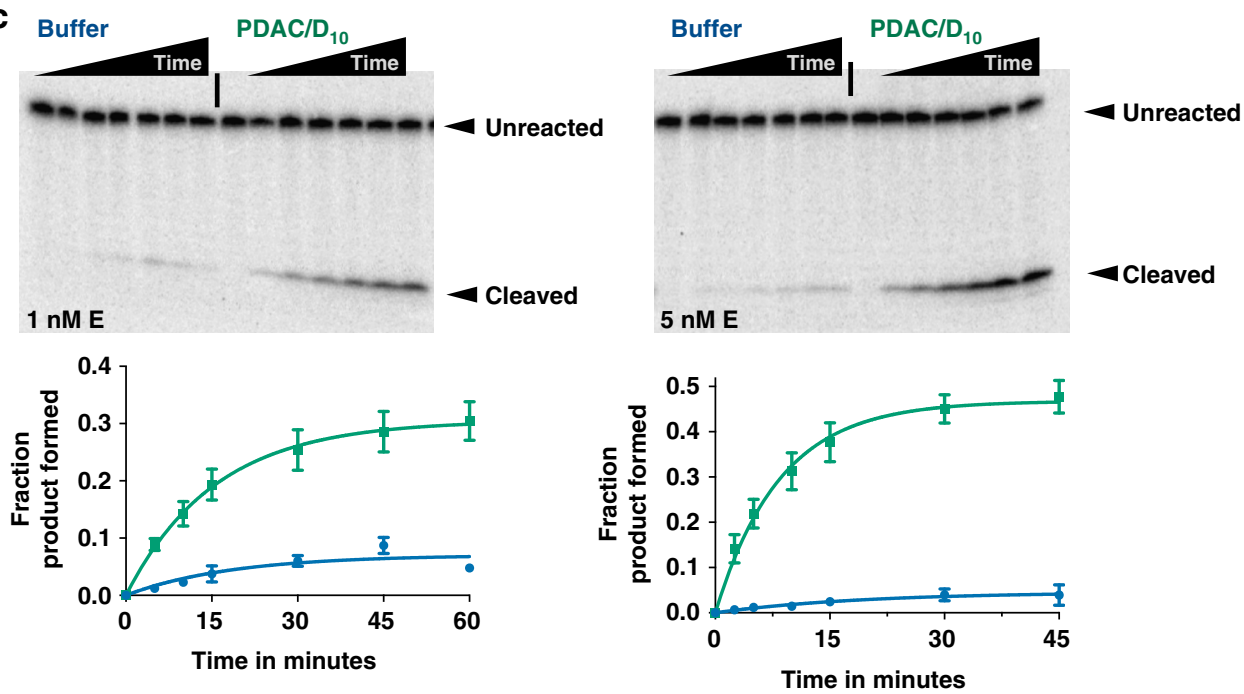

d
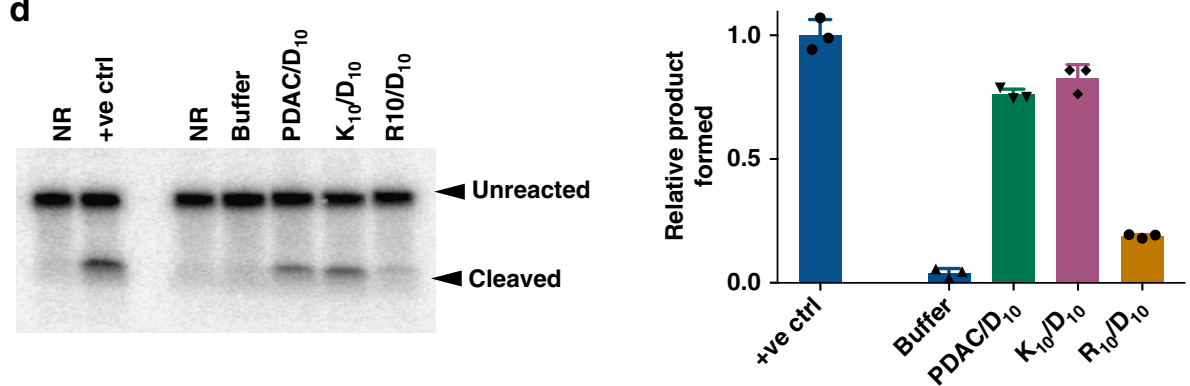

Fig. 5 Enhanced ribozyme activity in coacervates. a Structure of the hammerhead ribozyme-substrate complex. The cleavage site is indicated with red arrow. $\mathbf{b}$ Gel images showing ribozyme cleavage at different $\mathrm{Mg}^{2+}$ concentrations in the coacervate phase after $1 \mathrm{~h}$. Dilute and coacervate phases were separated immediately after the reaction initiation. Reactions contained $25 \mathrm{mM}$ Tris. $\mathrm{HCl} \mathrm{pH} \mathrm{8.0,5} \mathrm{mM} \mathrm{NaCl}$ and indicated $\mathrm{Mg}^{2+}$. c Representative gel images showing ribozyme cleavage in buffer or in PDAC-53/ $\mathrm{D}_{10}$ coacervates at $1 \mathrm{nM}$ and $5 \mathrm{nM}$ ribozyme concentration; data were quantified from the gels above and fit to Eq. (1). Reactions in buffer (blue trace) and PDAC/ $\mathrm{D}_{10}$ coacervates (green trace) were performed at room temperature in $25 \mathrm{mM}$ Tris- $\mathrm{HCl}$ $\mathrm{pH} 8.0,1 \mathrm{mM} \mathrm{MgCl}_{2}$, and $2.5 \mathrm{mM} \mathrm{KCl}$. For 1 and $5 \mathrm{nM}$ enzyme, observed rate constants are $0.05 \pm 0.02$ and $0.05 \pm 0.02 \mathrm{~min}^{-1}$ for reactions in buffer and $0.06 \pm 0.01$ and $0.12 \pm 0.01$ for reactions in coacervates. $\mathbf{d}$ Representative gel image showing ribozyme cleavage after $1 \mathrm{~h}$ of reaction in $25 \mathrm{mM}$ Tris- $\mathrm{HCl} \mathrm{pH}$ $7.5,1 \mathrm{mM} \mathrm{MgCl}{ }_{2}$, and $2.5 \mathrm{mM} \mathrm{KCl}$. NR contained no ribozyme, +ve ctrl contained $250 \mathrm{nM}$ ribozyme, and all other lanes contained $2.5 \mathrm{nM}$ enzyme. Coacervates contained $15 \mathrm{mM}$ total positive charge from various polycations and $15 \mathrm{mM}$ total negative charge from $\mathrm{D}_{10}$. Product yields were normalized to "+ve ctrl". All error bars represent S.E.M. $(n=3)$ from three independent experiments. Uncropped gel images are shown in Supplementary Figure 16a, b

primer-template complex and/or disorient the $3^{\prime} \mathrm{OH}$ such that the $3^{\prime} \mathrm{O}$ of primer and the $\mathrm{P}-5^{\prime} \mathrm{O}$ bonds are not in line for the nucleophilic attack. Oligoarginine significantly inhibited the reaction whereas oligolysine with the same number of residues did not, although the longer oligolysine $\left(\mathrm{K}_{100}\right)$ did. Arginine can interact extensively with nucleic acids, especially guanine nucleotides in bidentate interactions with $\mathrm{O}-6$ and $\mathrm{N}-7^{35}$, possibly interfering with the base-pairing within the primer-template complex and also potentially with the $2-\mathrm{Me}-\mathrm{ImpG}$ monomer. The quaternary amine PDAC lacks H-bonding capabilities and has a buried positive charge and therefore may not actively interact with nucleic acids in an inhibitory manner. Although the prebiotic origin of PDAC is not yet known, pyrrolidine, which resembles the unmethylated monomer of PDAC, has been detected in meteorite samples ${ }^{43}$. While PDAC/RNA coacervates outperformed others, it should be emphasized that templatedpolymerization did occur in $\mathrm{K}_{10} / \mathrm{RNA}$ coacervates, albeit at slightly reduced levels. Furthermore, when coacervates coexisted 
a Unimolecular hairpin ribozyme with interdomain interactions
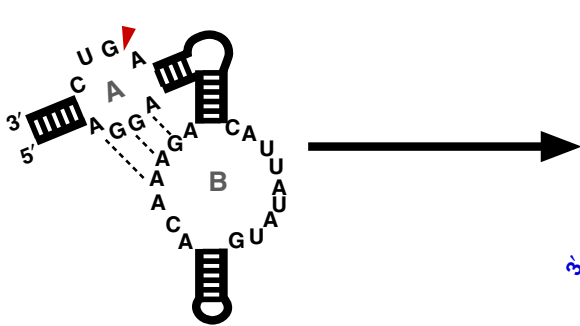

के

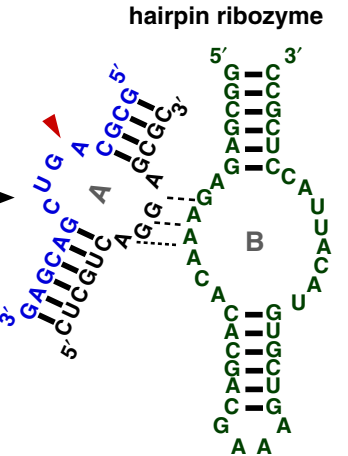

b

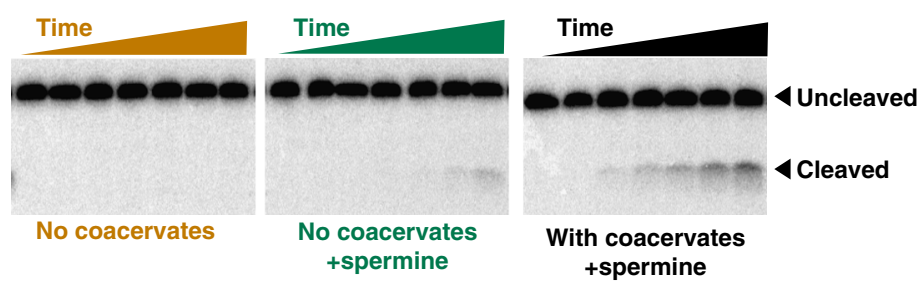

Multi-domain split hairpin ribozyme

+spermine
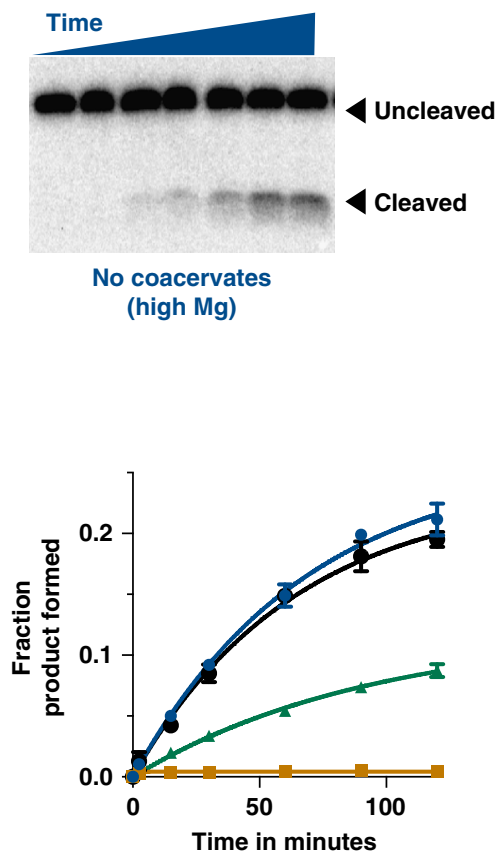

Fig. 6 Concentration of cofactors in coacervates enhances of hairpin ribozyme catalysis. a Consensus secondary structure of the unimolecular hairpin ribozyme with conserved nucleotides (left), the site for cleavage is indicated with red arrowhead. Multi-domain split hairpin ribozyme where loop A consists of the substrate (blue) and the substrate-binding strand (black) and loop B domains separated (green). Gel image showing cleavage of the substrate is shown. Reaction were performed in buffer containing $25 \mathrm{mM}$ Tris- $\mathrm{HCl} \mathrm{pH} \mathrm{7.5,25 \textrm {mM } \mathrm { MgCl }}$ and $25 \mathrm{mM} \mathrm{KCl}$. Reactions contained $1 \mathrm{nM}$ substrate, $1 \mu \mathrm{M}$ substrate-binding strand, and $1 \mu \mathrm{M}$ of the loop B domain. $\mathbf{b}$ Substrate cleavage of loop A domain by the ribozyme at sub-optimal conditions. All reactions were performed in $25 \mathrm{mM}$ Tris. $\mathrm{HCl} \mathrm{pH} \mathrm{7.5,2.5} \mathrm{mM} \mathrm{MgCl}$, and $2.5 \mathrm{mM} \mathrm{KCl}$ with additional components as indicated. Reactions contained $1 \mathrm{nM}$ substrate, $50 \mathrm{nM}$ substrate-binding strand, and $25 \mathrm{nM}$ of the loop B domain. Coacervates were formed by PDAC-53 and spermine at $5 \mathrm{mM}$ total positive charge from each and $10 \mathrm{mM}$ total negative charge from polyaspartic acid $\left(D_{30}\right)$. Time points were taken at $0,2.5,15,30,60,90$, and 120 min. Plots showing fraction product cleaved versus time is shown in right. Fractions product formed were fit to Eq. (1). Colors in the plot correspond to labels of gel images. All error bars represent S.E.M. $(n=3)$ from three independent experiments. Uncropped gel images are shown in Supplementary Figure 17a

with the dilute phase, templated-polymerization in $\mathrm{K}_{10} / \mathrm{RNA}$ and PDAC/RNA were identical to buffer conditions while encapsulating over $65 \%$ of the RNA in the coacervate phase. These observations coupled with the recent report of hammerhead catalysis in pLys/CM-Dex coacervates ${ }^{30}$ suggest that RNA chemistries can occur in a wide range of coacervate compositions and that the chemistry of a particular coacervate will impact its effectiveness as a reaction compartment.

One of the intriguing observations was that at reduced or no $\mathrm{Mg}^{2+}$, PDAC-53/ $\mathrm{rA}_{11}$ coacervates and PDAC-53 alone stimulated template-directed polymerization compared to buffer. Since PDAC does not have proton donating or accepting capabilities to act as general acid or general base, the enhancement in reaction could be from charge stabilization of the transition state provided by the positively charged nitrogens of PDAC. These data suggest that coacervate systems can actively participate in the chemistry rather than simply acting as a "compartment" for reactions. To the best of our knowledge, polyamine-dependent enhancement of template-directed polymerization has not been reported; however, enhancement of ribozyme cleavage from spermidine at limiting ${ }^{44}$ and in the absence ${ }^{41}$ of magnesium has been observed. Typically, molar amounts of monovalent are required to substitute for magnesium in ribozyme reactions ${ }^{45,46}$. Coacervates may provide the unique ionic conditions required for activity by concentrating ions. We estimated roughly a 5 -fold increase in $\mathrm{Mg}^{2+}$ inside PDAC/ $/ \mathrm{A}_{11}$ coacervates, and $\mathrm{Mg}^{2+}$ bound weakly to the polyanions may still be available for template-directed polymerization and other related chemistries ${ }^{47}$.
Differential RNA diffusions in PDAC and $\mathrm{R}_{10}$ coacervates as observed in FRAP experiments indicate that specific coacervates may provide unique environments and have varying degree of RNA-coacervate interactions. Apparent diffusion coefficients reported here for PDAC-53/rA 11 and $\mathrm{R}_{10} / \mathrm{rA}_{11}$ are about 400 -fold lower compared to spermine/polyU RNA systems where different 15 -mer RNAs were used as fluorescent probes ${ }^{18}$. This is likely due to differences in coacervate composition; for example, about 40fold difference in fluorescence recovery time-constant from FRAP experiments for the same RNA probe in pLys/ATP and pLys/ CM-Dextran coacervates has been reported ${ }^{30}$.

An important consideration for a model protocell during the RNA world is that it should be able to maintain activities of compartmentalized aptamers or ribozymes within the protocells. The activity of the fluorescent RNA aptamer inside the coacervate droplets unambiguously shows that $\mathrm{PDAC} / \mathrm{rA}_{11}$ coacervates support folded RNA secondary and tertiary structures, which is required for many RNA functions. We have shown herein that $\mathrm{PDAC} / \mathrm{rA}_{11}$ coacervates retain activity of hammerhead ribozyme. Reduced ribozyme activity has recently been reported for the hammerhead cleavage in coacervates made with polylysine and carboxylated dextran ${ }^{30}$ at saturating enzyme concentrations. Under those conditions, about 13 -fold to 60 -fold reductions in observed rate constants were reported depending on whether the reactions were carried out in microdroplets or in bulk coacervates. Interestingly, in our study, at low ribozyme concentrations, we observe enhancements in ribozyme cleavage yields in the presence of coacervates at all times points. Enhancement of 


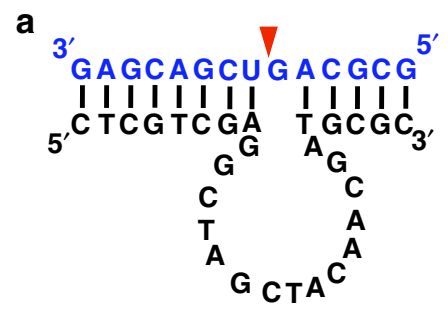

b

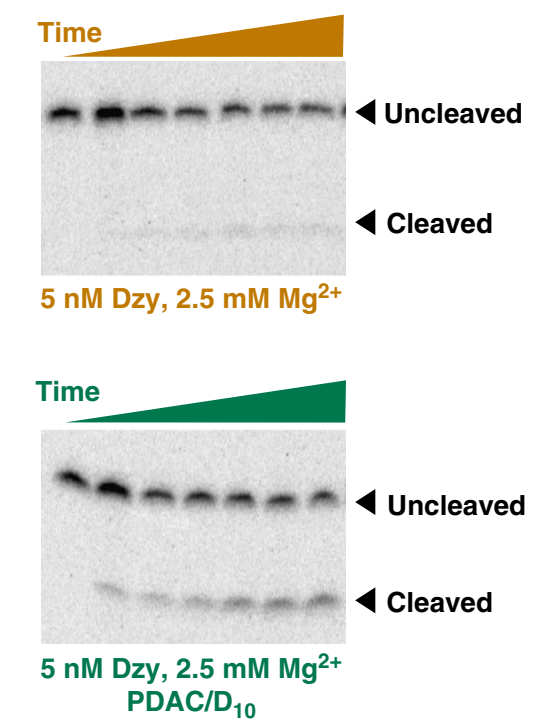

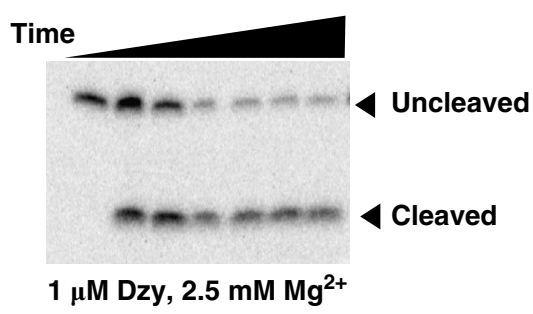

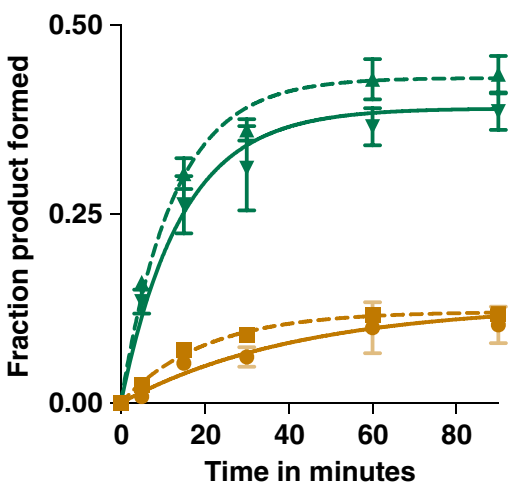

Fig. 7 Coacervate-mediated stimulation of a DNAzyme. a Structure of the 10-23 DNAzyme. The enzyme strand is shown in black and the substrate is shown in blue. The red arrow indicates the cleavage site. Gel image shows efficient cleavage of the substrate $(0.25 \mathrm{pM})$ by the enzyme $(1 \mu \mathrm{M})$ in $25 \mathrm{mM}$ Tris- $\mathrm{HCl} \mathrm{pH} 8.0$ containing $2.5 \mathrm{mM} \mathrm{MgCl}_{2}$ and $2.5 \mathrm{mM} \mathrm{KCl}$. Time points were taken at $0,2.5,5,15,30,60$, and $90 \mathrm{~min}$. b Reactions contained $5 \mathrm{nM}$ of the enzyme strand and $0.25 \mathrm{pM}$ substrate strand in $25 \mathrm{mM}$ Tris- $\mathrm{HCl}$ pH 8.0 containing $2.5 \mathrm{mM} \mathrm{MgCl}_{2}$ and $2.5 \mathrm{mM} \mathrm{KCl}$. Coacervates were formed by adding PDAC-53 and $\mathrm{D}_{10}$ at $10 \mathrm{mM}$ total charge from each. Time points were taken at 0, 5, 15, 30, 60, 90, and 120 min. Fraction product formed were calculated from gels shown in b and Supplementary Figure 13 and data were fit to Eq. (1). Green solid and dashed lines indicate experiments performed in $2.5 \mathrm{mM} \mathrm{Mg}^{2+}$ or $5 \mathrm{mM} \mathrm{Mg} \mathrm{M}^{2+}$, respectively. All error bars represent S.E.M. $(n=3)$ from three independent experiments. Uncropped gel images are shown in Supplementary Figure 17b

the hammerhead ribozyme was also observed for $\mathrm{K}_{10} / \mathrm{D}_{10}$ coacervates. On a similar note, stimulation of the hairpin ribozyme by spermine-containing coacervates and enhancement of the DNAzyme cleavage by $\mathrm{PDAC} / \mathrm{D}_{10}$ coacervates suggest that coacervate-dependent activation may be useful for reactions catalyzed by diverse biopolymers and that coacervate-dependent activation is not limited to PDAC-containing coacervates. Taken together, our study suggests that coacervates can potentiate functions of RNA and other biopolymers under sub-optimal enzyme and ion conditions by concentrating biomolecules and solutes, which would have been critical in the early RNA world where concentrations of functional RNAs may have been scarce.

It has been previously demonstrated that protein kinases can phosphorylate polyions such as cationic peptides or ADP to trigger dissolution of complex coacervates, which can be reversed by phosphatase enzymes ${ }^{48,49}$. In an "RNA World", a ribozyme with kinase $e^{3,50}$ or phosphatase activity could have performed similar roles by modulating charge densities on polymers through covalent modification ${ }^{4}$. Transient coacervation of metabolic enzymes and their substrates could have provided micro-reactor compartments for specific reactions that may otherwise be inaccessible in dilute solutions.

\section{Methods}

Reagents and synthesis. Poly(allyl)amine hydrochloride (PAH) $15 \mathrm{kDa}$, protamine sulfate, and polyacrylic acid ( $1.8 \mathrm{kDa})$ were purchased from Sigma (St. Louis). Polydiallyldimethylammonium chloride (PDAC) $8.5 \mathrm{kDa}$ was purchased from Polysciences (Warrington, PA). Oligolysine, oligoarginine, and oligoaspartic acid were purchased from Alamanda polymers (Huntsville, AL) as chloride or sodium salts. Charge density calculated by assuming that all the protonable nitrogen atoms in the polymer are protonated at the reaction $\mathrm{pH}$. $\mathrm{pKas}$ for monomer ionizable groups of $\mathrm{PAH}, \mathrm{R}_{10}$, and $\mathrm{K}_{10}$ are $8.8^{51}, 12.48^{52}$, and $10.53^{52}$, respectively. RNA primer and templates were purchased from IDT (Coralville, IA). Oligoadenosine (rA11) was purchased from Trilink Biotechnologies (San Diego, CA). Guanosine monophosphate was purchased from MP Biomedicals. 2-Me-ImpG was synthesized as previously described ${ }^{53}$, with some modifications. In brief, $100 \mathrm{mg}$ of GMPfree acid and $240 \mathrm{mg}$ of 2-methyl imidazole were added to $20 \mathrm{ml}$ of DMSO and stirred at $50^{\circ} \mathrm{C}$. To the solution of GMP, $0.75 \mathrm{~g}$ of triphenylphosphine, $0.85 \mathrm{~g}$ of aldrithiol-2, and $1.08 \mathrm{~mL}$ of triethylamine were added. Reactions were allowed to proceed for $1 \mathrm{~h}$ at room temperature. Then, the mixture was added dropwise to $100 \mathrm{~mL}$ solution of 1:1 acetone, diethyl ether containing $1.1 \mathrm{~g}$ sodium perchlorate to precipitate 2-Me-ImpG. Solution was then centrifuged at $5000 \times g$ for $5 \mathrm{~min}$ and

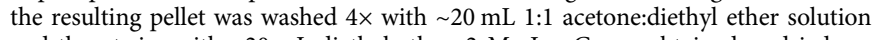
and then twice with $\sim 20 \mathrm{~mL}$ diethyl ether. 2-Me-ImpG was obtained as dried powder by vacuum centrifugation.

Template-directed polymerization. Template-directed reactions were assembled by first adding water and buffer $\left(1 \times=25 \mathrm{mM}\right.$ Tris- $\left.\mathrm{HCl} \mathrm{pH} \mathrm{8.0,5} \mathrm{mM} \mathrm{MgCl}_{2}\right)$. For reactions not containing any coacervates, cationic polymers were then added to 
indicated concentrations, 2-Me-ImpG was added to a final concentration of $10 \mathrm{mM}$, followed by addition of RNA primer-template complex $(1 \mu \mathrm{M}$ template and $<50 \mathrm{nM} \mathrm{5}$ labeled primer). For reactions done under coacervation conditions, the anionic component of the coacervate system was added following the addition of water and buffer. The total negative charge from the $\mathrm{rA}_{11}$ polyanion was held at 7.5 mM. 2-Me-ImpG was then added to a final concentration of $10 \mathrm{mM}$. Coacervation was induced by addition of different cationic polymers with total positive charge at $10 \mathrm{mM}$. Reactions were initiated by addition of RNA primer-template complex and incubated at room temperature for indicated times. The total negative charge from the RNA primer-template complex was $<20 \mu \mathrm{M}$.

Reactions were stopped by adding equal volume of "stopping solution", which contained $8.3 \mathrm{mM}$ polyacrylic acid $1.8 \mathrm{kDa}, 166 \mathrm{mM}$ EDTA and $333 \mathrm{mM} \mathrm{NaOH}$. Finally, one reaction volume of $90 \%$ formamide and $50 \mathrm{mM}$ EDTA solution was added after which samples were heated at $85^{\circ} \mathrm{C}$ for $1 \mathrm{~min}$ and separated by electrophoresis on a $20 \%$ denaturing polyacrylamide gel containing $7 \mathrm{M}$ Urea. Gels were dried and exposed to phosphorscreens, which were then scanned by Typhoon FLA 9000 (GE). Fraction of polymerized RNA primer was calculated by using the equation $A /(A+B)$, where $A$ is the sum of intensities for polymerized bands, and $B$ is the intensity of unreacted primer. For kinetic experiments, data were fit to first order exponential

$$
f(t)=f_{\max }\left(1-\mathrm{e}^{\left(-k_{\mathrm{obs}} \cdot t\right)}\right)
$$

where $f(t)$ is the fraction product formed at indicated time $t, f_{\max }$ is the plateau, and $k_{\text {obs }}$ is the observed rate constant. All fits were performed in GraphPad Prism 7. For reactions shown in Fig. $2 \mathrm{~b}$, samples were centrifuged immediately for $1 \mathrm{~min}$ at $14,000 \times g$ after addition of the RNA:primer-template complex. The resulting supernatant and the condensed phases were then separated and reactions were allowed to proceed in the respective phases for $5 \mathrm{~h}$ at room temperature.

Hammerhead ribozyme reactions in PDAC/rA 11 coacervates. Coacervates (10 $\mathrm{mM}$ charge balance) were assembled by adding water, buffer $(1 \times=25 \mathrm{mM}$ Tris- $\mathrm{HCl} \mathrm{pH} \mathrm{8.0,} 5 \mathrm{mM} \mathrm{NaCl}$ and $\left.0.1-1 \mathrm{mM} \mathrm{MgCl}_{2}\right), \mathrm{rA}_{11}$ and then PDAC-53. Ribozyme $(10 \mu \mathrm{M})$ and substrate $(\sim 100 \mathrm{nM})$ were added in folding buffer that did not contain any magnesium $(1 \times=25 \mathrm{mM}$ Tris- $\mathrm{HCl}, 5 \mathrm{mM} \mathrm{NaCl})$. The ribozyme-substrate complex was heated at $85^{\circ} \mathrm{C}$ for $3 \mathrm{~min}$ and allowed to cool at room temperature for $3 \mathrm{~min}$. Reactions were initiated by adding ribozyme:substrate complex to the $\mathrm{Mg}^{2+}$-containing coacervate solutions. Samples were immediately centrifuged at $14,000 \times g$ for $1 \mathrm{~min}$. Supernatant and the coacervate phases were separated and allowed to react for $1 \mathrm{~h}$ at room temperature. Reactions were stopped for supernatant solution by adding one reaction volume of "stopping solution", which contained $8.3 \mathrm{mM}$ polyacrylic acid $1.8 \mathrm{kDa}, 166 \mathrm{mM}$ EDTA and one reaction volume of formamide loading dye ( $90 \%$ formamide and $50 \mathrm{mM}$ EDTA). For coacervates, water (equal to initial reaction volume) was first added followed by addition of stopping solution. Samples were then heated at $90^{\circ} \mathrm{C}$ for $3 \mathrm{~min}$ and coacervate phase was disrupted by pipette mixing immediately after heating. Reactions were then separated by electrophoresis on a $15 \%$ denaturing polyacrylamide gel containing $8 \mathrm{M}$ Urea.

Hammerhead ribozyme reactions at low enzyme concentrations. Ribozymes and substrates at $10 \times$ of desired concentrations were separately heated at $85^{\circ} \mathrm{C}$ for $3 \mathrm{~min}$ in water, followed by addition of folding buffer $(1 \times=25 \mathrm{mM}$ Tris- $\mathrm{HCl} \mathrm{pH}$ $8.0,2.5 \mathrm{mM} \mathrm{KCl}$ ). Ribozyme and substrate were allowed to equilibrate at room temperature for $3 \mathrm{~min}$ and kept on ice. To obtain the zero time-point, $10 \times$ substrate was added to water. Coacervates $(10 \mathrm{mM}$ charge balance) were assembled by adding water, buffer $(1 \times=25 \mathrm{mM}$ Tris- $\mathrm{HCl} \mathrm{pH} 8.0,1 \mathrm{mM} \mathrm{MgCl} 2,2.5 \mathrm{mM} \mathrm{KCl})$, oligoaspartic acid $\mathrm{D}_{10}$ and PDAC-53. Renatured ribozyme was first added followed by the substrate to initiate the reactions. Reactions were then immediately aliquoted into tubes, and stopped at indicated times. Reactions were then separated by electrophoresis on a $15 \%$ denaturing polyacrylamide gel containing $8 \mathrm{M}$ Urea. Plots of fraction cleaved were fit to Eq. (1).

Estimation of RNA primer concentration inside coacervates. Standards of indicated Cy-3-labeled RNA primer were made in solutions of $25 \mathrm{mM}$ Tris- $\mathrm{HCl}$ $\mathrm{pH} 8.0,1 \mathrm{mM} \mathrm{MgCl}$. Indicated coacervates were made in $1 \mathrm{mM} \mathrm{MgCl}_{2}$ and $25 \mathrm{mM}$ Tris- $\mathrm{HCl} \mathrm{pH} \mathrm{8.0.} \mathrm{A} 10 \times$ primer-template complex was made by heating the $10 \mu \mathrm{M}$ Cy3-labeled primer and $15 \mu \mathrm{M}$ template in water at $85^{\circ} \mathrm{C}$ for $3 \mathrm{~min}$ followed by addition of $10 \times$ buffer $(1 \times=1 \mathrm{mM} \mathrm{MgCl}$ and $25 \mathrm{mM}$ Tris-HCl pH 8.0). Solution was left at room temperature for $5 \mathrm{~min}$ to equilibrate. Indicated coacervates were prepared, and renatured primer-template complex was added such that the primer concentration was $0.5 \mu \mathrm{M}$ in the coacervate solution. Overall, $8 \mu \mathrm{L}$ of the solution was placed on a glass slide and mounted on a Leica TCS SP5 laser scanning confocal inverted microscope (LSCM) with a $\times 63$ objective lens. A $543 \mathrm{~nm}$ laser was used for excitation and emission spectra were collected from 560 to $600 \mathrm{~nm}$. Leica LAS AF software was used to acquire the images.

Estimation of coacervate phase volume. Standards of $0.5,1,1.5$, and $2 \mu \mathrm{L}$ were prepared by adding indicated amount of Cy3-labeled-RNA primer. These were then centrifuged briefly to ensure that the samples were at the bottom of the tube A total of $20 \mu \mathrm{L}$ bulk coacervates of PDAC and rA11 were prepared at $10 \mathrm{mM}$ charge balance in $25 \mathrm{mM}$ Tris- $\mathrm{HCl} \mathrm{pH} 8.0$ and $1 \mathrm{mM} \mathrm{MgCl}$. Cy3-labeled-RNA primer was added to a final concentration of $5 \mu \mathrm{M}$. Sample was then centrifuged to pellet the condensed phase Samples were placed on UV transilluminator (FOTODYNE Inc.) and irradiated with $312 \mathrm{~nm}$ UV while the images were collected. Coacervate phase volume was compared against the known standards by visual inspection.

Atomic absorption spectroscopy. Standards of $0,1,2.5,5$, and $10 \mu \mathrm{M} \mathrm{Mg}^{2+}$ were made using serially diluted commercial $1 \mathrm{M}$ Stock $\mathrm{MgCl}_{2}$ (Sigma) in water. Coacervates $(20 \mu \mathrm{L})$ were prepared in solutions containing $25 \mathrm{mM}$ Tris $\cdot \mathrm{HCl}$ and $5 \mathrm{mM}$ $\mathrm{MgCl}_{2}$ at $10 \mathrm{mM}$ charge balance. To measure depleted $\mathrm{Mg}^{2+}$, samples were centrifuged for $14,000 \times g$ for $2 \mathrm{~min}$, and $10 \mu \mathrm{L}$ of the supernatant was added to 9.99 $\mathrm{mL}$ of water. This was also done for samples that did not undergo centrifugation Samples were then analyzed using a Shimadzu Flame Atomic Absorption Spectrometer 7000. The uncertainty in coacervate volume was not accounted for in estimation of magnesium concentration.

Ribozyme concentration inside coacervates. Standards of indicated fluorescein were made in solutions of $1 \mathrm{mM} \mathrm{MgCl} 2$ and $2.5 \mathrm{mM} \mathrm{KCl}$. Hammerhead ribozyme was labeled on the $5^{\prime}$ end with fluorescein as described ${ }^{54}$. In short, in vitro transcribed RNA were treated with calf intestinal phosphatase (NEB) and phosphorylated using polynucleotide kinase (NEB) using ATP- $\gamma$ S. RNAs were then treated with 5-iodoacetamido-fluorescein (Sigma). Labeled RNA was purified using Sephadex G-25 column (GE). Efficiency of labeling and concentration of fluorescently tagged RNA was measured by comparing absorbance at 260 and $490 \mathrm{~nm}$. $\left(\varepsilon_{\mathrm{HHRz}}=448700 \mathrm{M}^{-1} \mathrm{~cm}^{-1}, \varepsilon_{\text {fluorescein }}=72500 \mathrm{M}^{-1} \mathrm{~cm}^{-1}\right)$ and calculated to be $35 \%$. Coacervates of PDAC-53 and D10 were made at in $1 \mathrm{mM} \mathrm{MgCl}_{2}$ and $2.5 \mathrm{mM}$ $\mathrm{KCl}$ and indicated concentrations of fluorescently labeled RNA was added to the droplets. Samples were then imaged as previously described. Overall, $488 \mathrm{~nm}$ laser was used for excitation, and the emission window was set from 510 to $550 \mathrm{~nm}$.

Isothermal binding of the hammerhead ribozyme and substrate. Samples

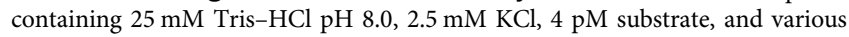
concentrations of enzyme ranging from 0 to $17.5 \mu \mathrm{M}$ were incubated at $85^{\circ} \mathrm{C}$ for $3 \mathrm{~min}$ and then placed at room temperature for a minimum of $3 \mathrm{~min}$. Each sample was then mixed with $\mathrm{MgCl}_{2}$ to a final concentration of $1.0 \mathrm{mM}$ or $25 \mathrm{mM}$ and subsequently placed on ice. The RNA was fractionated using native PAGE at $25^{\circ} \mathrm{C}$ and imaged via phosphorimager. Fraction of substrate bound at indicated enzyme concentration was determined by quantification of the bands (ImageJ). Data were fit to

$$
f_{\mathrm{b}}=\frac{B_{\max } \cdot X}{K_{\mathrm{d}}+X}+C
$$

where $f_{\mathrm{b}}$ is the fraction bound, $B_{\max }$ is the maximum bound, $K_{\mathrm{d}}$ is the dissociation constant, $X$ is the concentration of the enzyme and $C$ is a constant.

\section{Fluorescence recovery after photobleaching (FRAP). After preparing coa-} cervates as described, droplets for FRAP analysis were chosen in the FRAP Wizard interface in the Leica LAS AF software. A region of interest (ROI) of $1 \mu \mathrm{M}$ diameter was defined for fluorescence measurements during pre-bleach, bleach, and postbleach sequences. Overall, 5 frames at $0.50 \mathrm{~s} /$ frame pre-bleach, 5 frames at $0.19 \mathrm{~s} /$ frame during bleach, and 300 frames at $0.5 \mathrm{~s} /$ frame post-bleach were acquired. Laser power was set at $100 \%$ for $458,476,488,514,543$, and $633 \mathrm{~nm}$ lasers for bleach. Fluorescence intensities during the pre-bleach, bleach, and post-bleach sequences were measured in FIJI (Fiji Is Just ImageJ) to generate recovery curves. Recovery data were normalized as described by Jia et al. ${ }^{19}$ by using the equation:

$$
F(t)=\frac{[S(t)-B(t)]-[R(o)-B(o)]}{[R(t)-B(t)]-[S(o)-B(o)]},
$$

where $F(t)$ is the normalized fluorescence intensity of the ROI at the given time. $S(t)$ is the intensity within the chosen sample ROI for bleaching; $R(t)$, the intensity within a different droplet that is not bleached; and $B(t)$, is the intensity of the background ROI.

Data were then fit to the first order exponential

$$
f(t)=A\left(1-\mathrm{e}^{(-t / \tau)}\right)+C
$$

where $f(t)$ is the normalized fluorescence at time $t, A$ is the amplitude of recovery, and $C$ is the $Y$-intercept. Half-lives $\left(t_{(1 / 2)}\right)$ of fluorescence recovery was calculated by using $t_{(1 / 2)}=\ln (2)^{*} \tau$. Apparent diffusion coefficient $\left(D_{\text {app }}\right)$ was calculated by the formula $D_{\text {app }}=\left(0.88 \omega^{2}\right) / 4 \cdot t_{1 / 2}$, where $\omega$ is the radius of the bleached ROI.

Fluorescence of stabilized dimeric broccoli (sdB). The stabilized dimeric broccoli aptamer (GAGGGAGACGGUCGGGUCCAUCUGAGACGGUCGGGU 
CCAGAUAUUCGUAUCUGUCGAGUAGAGUGUGGGCUCAGAUGUCGAG UAGAGUGUGGGCUCCCUC) was transcribed in vitro, purified by PAGE and concentrated by ethanol precipitation. The bolded and underlined Gs were mutated to $\mathrm{Cs}$ for the inactive mutant. RNA was renatured by heating in water at $85^{\circ} \mathrm{C}$ for $3 \mathrm{~min}$, followed by immediately adding the $10 \times$ buffer $(1 \times=25 \mathrm{mM}$ Tris $-\mathrm{HCl} \mathrm{pH}$ $8.0,5 \mathrm{mM} \mathrm{MgCl}$, and $5 \mathrm{mM} \mathrm{KCl}$ ). RNA was left at room temperature for $5 \mathrm{~min}$ after which, the DFHBI dye was added, and samples were left on ice until ready to be mixed with coacervate solutions. PDAC and rA11 coacervates were made as previously described. Overall, $1 \mu \mathrm{L}$ of the folded RNA was added to $14 \mu \mathrm{L}$ of the coacervate solution, and $10 \mu \mathrm{L}$ of this sample was used to prepare slides. For samples in which $s \mathrm{~dB}$ or DFHBI were added separately, coacervates were first formed after adding either DFHBI or folded $\mathrm{sdB}$, then the other component was added. $15 \%$ of 453 and $476 \mathrm{~nm}$ lasers were used together for excitation, and the emission window was set at $500-550 \mathrm{~nm}$. For bulk measurements, fluorescence of samples in the presence and absence of coacervates was measured at $15^{\circ} \mathrm{C}$ in Applied Biosystem StepOne Plus qPCR machine using emission filter for Fluorescein amidite $(\mathrm{FAM})(\mathrm{Em} . \mathrm{Max}=520 \mathrm{~nm})$

Hairpin ribozyme reaction. $10 \times$ solutions of ribozyme (loop B) was prepared in $25 \mathrm{mM}$ Tris- $\mathrm{HCl} \mathrm{pH} 7.51 .25 \mathrm{mM} \mathrm{MgCl} 2$ and $1.25 \mathrm{mM} \mathrm{KCl}$. Ribozyme solution were first heated to $85^{\circ} \mathrm{C}$ for $3 \mathrm{~min}$ and equilibrated at room temperature for $5-10$ min. Similarly, $5 \times$ solutions of the substrate-substrate-binding strand complex was also prepared in the same buffer and renatured separately. PDAC-53, Spermine and $\mathrm{D}_{30}$ were first assembled in $25 \mathrm{mM}$ Tris pH 7.5 with either $25 \mathrm{mM} \mathrm{MgCl} 2$ and $25 \mathrm{mM} \mathrm{KCl}$ (high $\mathrm{Mg}$ ) or $2.5 \mathrm{mM} \mathrm{MgCl}_{2}$ and $2.5 \mathrm{mM} \mathrm{KCl}$ (low $\mathrm{Mg}$ ). $10 \times$ solution of ribozyme was added to indicated final concentrations followed by addition of the $5 \times$ substrate-substrate-binding strand complex to initiate the reaction. Reactions were stopped by adding two volumes of the stopping solution which contained $8.3 \mathrm{mM}$ polyacrylic acid $1.8 \mathrm{kDa}, 166 \mathrm{mM}$ EDTA, and one volume of $90 \%$ formamide loading dye.

DNAzyme reactions. 10x solutions of DNAzyme was prepared in $25 \mathrm{mM}$ Tris- $\mathrm{HCl} \mathrm{pH} 8.0$ and $2.5 \mathrm{mM} \mathrm{KCl}$. DNAzyme solutions were first heated to $85^{\circ} \mathrm{C}$ for $3 \mathrm{~min}$ and equilibrated at room temperature for 5-10 min. Similarly, 10x solutions of the substrate was also prepared in the same buffer and renatured separately. PDAC- $53, \mathrm{D}_{10}$ were first assembled in $25 \mathrm{mM}$ Tris $\mathrm{pH} 8.0$ with either $2.5 \mathrm{mM} \mathrm{MgCl}_{2}$ and $2.5 \mathrm{mM} \mathrm{KCl}$ or $5 \mathrm{mM} \mathrm{MgCl}_{2}$ and $5 \mathrm{mM} \mathrm{KCl}$. $10 \times$ solution of ribozyme was added to indicated final concentrations followed by addition of the $10 \times$ substrate strand to initiate the reaction. Reactions were stopped by adding two volumes of the stopping solution which contained $8.3 \mathrm{mM}$ polyacrylic acid $1.8 \mathrm{kDa}$, $166 \mathrm{mM}$ EDTA, and one volume of $90 \%$ formamide loading dye.

Reporting Summary. Further information on experimental design is available in the Nature Research Reporting Summary linked to this Article.

\section{Data availability}

The authors declare that data supporting the findings of this study are available within the paper and its Supplementary Information files. All relevant data are available from the corresponding authors upon reasonable request.

Received: 16 August 2018 Accepted: 2 January 2019

Published online: 30 January 2019

\section{References}

1. Joyce, G. F. The antiquity of RNA-based evolution. Nature 418, 212-221 (2002).

2. Benner, S. A. \& Ellington, A. D. Modern metabolism as a palimpsest of the RNA world. Proc. Natl Acad. Sci. USA 86, 7054-7058 (1989).

3. Lorsch, J. R. \& Szostak, J. W. In vitro evolution of new ribozymes with polynucleotide kinase activity. Nature 371, 31-36 (1994).

4. Poudyal, R. R. et al. Selective inactivation of functional RNAs by ribozymecatalyzed covalent modification. ACS Synth. Biol. 6, 528-534 (2017).

5. Tuerk, C., MacDougal, S. \& Gold, L. RNA pseudoknots that inhibit human immunodeficiency virus type 1 reverse transcriptase. Proc. Natl Acad. Sci. USA 89, 6988-6992 (1992).

6. Zaug, A. J. \& Cech, T. R. Analysis of the structure of tetrahymena nuclear RNAs in vivo: telomerase RNA, the self-splicing rRNA intron, and U2 snRNA. RNA 1, 362-374 (1995).

7. Biondi, E., Nickens, D., Warren, S., Saran, D. \& Burke, D. H. Convergent donor and acceptor substrate utilization among kinase ribozymes. Nucleic Acids Res. 36, 6785-6795 (2010).

8. Biondi, E. et al. Lewis acid catalysis of phosphoryl transfer from a copper(II)NTP complex in a kinase ribozyme. Nucleic Acids Res. 41, 3327-3338 (2013).
9. Seelig, B. \& Jäschke, A. A small catalytic RNA motif with Diels-Alderase activity. Chem. Biol. 6, 167-176 (1999).

10. Izgu, E. C. et al. N-carboxyanhydride-mediated fatty acylation of amino acids and peptides for functionalization of protocell membranes. J. Am. Chem. Soc. 138, 16669-16676 (2016)

11. Mansy, S. S. \& Szostak, J. W. Reconstructing the emergence of cellular life through the synthesis of model protocells. Cold Spring Harb. Symp. Quant. Biol. 74, 47-54 (2009).

12. Adamala, K. \& Szostak, J. Nonenzymatic template-directed RNA synthesis inside model protocells. Science 432, 1098-1100 (2013).

13. Mansy, S. S. Membrane transport in primitive cells. Cold Spring Harb. Perspect. Biol. 2, a002188 (2010).

14. Keating, C. D. Aqueous phase separation as a possible route to compartmentalization of biological molecules. Acc. Chem. Res. 45, 2114-2124 (2012).

15. Oparin, A. I. The Origin of Life on the Earth (Oliver \& Boyd, Edinburgh \& London, 1957).

16. Koga, S., Williams, D. S., Perriman, A. W. \& Mann, S. Peptide-nucleotide microdroplets as a step towards a membrane-free protocell model. Nat. Chem. 3, 720-724 (2011).

17. Frankel, E. A., Bevilacqua, P. C. \& Keating, C. D. Polyamine/nucleotide coacervates provide strong compartmentalization of $\mathrm{Mg}^{2+}$, nucleotides, and RNA. Langmuir 32, 2041-2049 (2016).

18. Aumiller, W. M. Jr., Pir Cakmak, F., Davis, B. W. \& Keating, C. D. RNA-based coacervates as a model for membraneless organelles: formation, properties, and interfacial liposome assembly. Langmuir 32, 10042-10053 (2016).

19. Jia, T. Z., Hentrich, C. \& Szostak, J. W. Rapid RNA exchange in aqueous twophase system and coacervate droplets. Orig. Life Evol. Biospheres 44, 1-12 (2014).

20. Fox, S. W. The evolutionary significance of phase-separated microsystems. Orig. Life 7, 49-68 (1976).

21. Poudyal, R. R., Pir Cakmak, F., Keating, C. D. \& Bevilacqua, P. C. Physical principles and extant biology reveal roles for RNA-containing membraneless compartments in origins of life chemistry. Biochemistry 57, 2509-2519 (2018).

22. Marko, J. F. The liquid drop nature of nucleoli. Nucleus 3, 115-117 (2012).

23. Smith J. et al. Spatial patterning of $P$ granules by RNA-induced phase separation of the intrinsically disordered protein MEG-3. eLife 5, e21337 (2016).

24. Lin, Y., Protter, D. S., Rosen, M. K. \& Parker, R. Formation and maturation of phase-separated liquid droplets by RNA-binding proteins. Mol. Cell $\mathbf{6 0}$, 208-219 (2015).

25. Brangwynne, C. P., Tompa, P. \& Pappu, R. V. Polymer physics of intracellular phase transitions. Nat. Phys. 11, 899-904 (2015).

26. Fu, J., Fares, H. M. \& Schlenoff, J. B. Ion-pairing strength in polyelectrolyte complexes. Macromolecules 50, 1066-1074 (2017).

27. Katz, A. M. et al. Spermine condenses DNA, but not RNA duplexes. Biophys J. 112, 22-30 (2017).

28. Strulson, C. A., Molden, R. C., Keating, C. D. \& Bevilacqua, P. C. RNA catalysis through compartmentalization. Nat. Chem. 4, 941-946 (2012).

29. Nott, T. J., Craggs, T. D. \& Baldwin, A. J. Membraneless organelles can melt nucleic acid duplexes and act as biomolecular filters. Nat. Chem. 8, 569-575 (2016).

30. Drobot, B. et al. Compartmentalised RNA catalysis in membrane-free coacervate protocells. Nat. Commun. 9, 3643 (2018).

31. Tagami, S., Attwater, J. \& Holliger, P. Simple peptides derived from the ribosomal core potentiate RNA polymerase ribozyme function. Nat. Chem. $\mathbf{9}$, 325-332 (2017).

32. Kanavarioti, A., Baird, E. E. \& Smith, P. J. Use of phosphoimidazolideactivated guanosine to investigate the nucleophilicity of spermine and spermidine. J. Org. Chem. 60, 4873-4883 (1995).

33. Ilardo, M. A. \& Freeland, S. J. Testing for adaptive signatures of amino acid alphabet evolution using chemistry space. J. Syst. Chem. 5, 1 (2014).

34. Elbaum-Garfinkle, S. et al. The disordered P granule protein LAF-1 drives phase separation into droplets with tunable viscosity and dynamics. Proc. Natl Acad. Sci. USA 112, 7189-7194 (2015).

35. Blanco, C., Bayas, M., Yan, F. \& Chen, I. A. Analysis of evolutionarily independent protein-RNA complexes yields a criterion to evaluate the relevance of prebiotic scenarios. Curr. Biol. 28, 526-537 e525 (2018).

36. Huang, H. et al. A G-quadruplex-containing RNA activates fluorescence in a GFP-like fluorophore. Nat. Chem. Biol. 10, 686-691 (2014).

37. Filonov, G. S., Moon, J. D., Svensen, N. \& Jaffrey, S. R. Broccoli: rapid selection of an RNA mimic of green fluorescent protein by fluorescence-based selection and directed evolution. J. Am. Chem. Soc. 136, 16299-16308 (2014).

38. Deng, N. N. \& Huck, W. T. S. Microfluidic formation of monodisperse coacervate organelles in liposomes. Angew. Chem. Int. Ed. Engl. 56, 9736-9740 (2017). 
39. Alam, K. K., Tawiah, K. D., Lichte, M. F., Porciani, D. \& Burke, D. H. A fluorescent split aptamer for visualizing RNA-RNA assembly in vivo. ACS Synth. Biol. 6, 1710-1721 (2017).

40. Heckman, J. E. Reconstitution of hairpin ribozyme activity following separation of functional domains. J. Biol. Chem. 270, 29648-29651 (1995).

41. Earnshaw, D. J. \& Gait, M. J. Hairpin ribozyme cleavage catalyzed by aminoglycoside antibiotics and the polyamine spermine in the absence of metal ions. Nucleic Acids Res. 26, 5551-5561 (1998).

42. Santoro, S. W. \& Joyce, G. F. A general purpose RNA-cleaving DNA enzyme. Proc. Natl Acad. Sci. 94, 4262-4266 (1997).

43. Aponte, J. C., McLain, H. L., Dworkin, J. P. \& Elsila, J. E. Aliphatic amines in Antarctic CR2, CM2, and CM1/2 carbonaceous chondrites. Geochim. Cosmochim. Acta 189, 296-311 (2016).

44. Chowrira, B. M., Berzal-Herranz, A. \& Burke, J. M. Ionic requirements for RNA binding, cleavage, and ligation by the hairpin ribozyme. Biochemistry 32, 1088-1095 (1993).

45. Murray, J. B., Seyhan, A. A., Walter, N. G., Burke, J. M. \& Scott, W. G. The hammerhead, hairpin and VS ribozymes are catalytically proficient in monovalent cations alone. Chem. Biol. 5, 587-595 (1998).

46. Nakano, S., Chadalavada, D. M. \& Bevilacqua, P. C. General acid-base catalysis in the mechanism of a hepatitis delta virus ribozyme. Science 287, 1493-1497 (2000).

47. Yamagami, R., Bingaman, J. L., Frankel, E. A. \& Bevilacqua, P. C. Cellular conditions of weakly chelated magnesium ions strongly promote RNA stability and catalysis. Nat. Commun. 9, 2149 (2018).

48. Aumiller, W. M. Jr. \& Keating, C. D. Phosphorylation-mediated RNA/peptide complex coacervation as a model for intracellular liquid organelles. Nat. Chem. 8, 129-137 (2016).

49. Nakashima, K. K., Baaij, J. F. \& Spruijt, E. Reversible generation of coacervate droplets in an enzymatic network. Soft Matter 14, 361-367 (2018).

50. Poudyal, R. R. et al. Nucleobase modification by an RNA enzyme. Nucleic Acids Res. 45, 1345-1354 (2017).

51. Choi, J. \& Rubner, M. F. Influence of the degree of ionization on weak polyelectrolyte multilayer assembly. Macromolecules 38, 116-124 (2005).

52. Campbell, M. \& Farrell, S. Biochemistry (Cengage Learning, Belmont, CA, 2007).

53. Joyce, G. F., Inoue, T. \& Orgel, L. E. Non-enzymatic template-directed synthesis on RNA random copolymers. Poly (C, U) templates. J. Mol. Biol. 176, 279-306 (1984).

54. Zearfoss, N. R. \& Ryder, S. P. End-labeling oligonucleotides with chemical tags after synthesis. Methods Mol. Biol. 941, 181-193 (2012).

55. Zadeh, J. N. et al. NUPACK: Analysis and design of nucleic acid systems. J. Comput. Chem. 32, 170-173 (2011).

\section{Acknowledgements}

This work was supported by a grant (290363) from the Simons Foundation to R.R.P. and by NASA grant (80NSSC17K0034)

\section{Author contributions}

R.R.P., P.C.B. and C.D.K. conceived and designed experiments. R.R.P. performed template-directed polymerization, AAS, FRAP, fluorescent RNA aptamer, and nucleic acid enzyme experiments. R.M.G.-M. performed fluorescent RNA aptamer experiments A.J.V. performed hammerhead ribozyme-substrate-binding experiments. E.A.F. performed pilot experiments on hammerhead ribozymes. R.R.P., P.C.B. and C.D.K. wrote and edited the manuscript.

\section{Additional information}

Supplementary Information accompanies this paper at https://doi.org/10.1038/s41467 019-08353-4.

Competing interests: The authors declare no competing interests.

Reprints and permission information is available online at http://npg.nature.com/ reprintsandpermissions/

Journal peer review information: Nature Communications thanks the anonymous reviewers for their contribution to the peer review of this work. Peer reviewer reports are available.

Publisher's note: Springer Nature remains neutral with regard to jurisdictional claims in published maps and institutional affiliations.

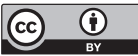

Open Access This article is licensed under a Creative Commons Attribution 4.0 International License, which permits use, sharing, adaptation, distribution and reproduction in any medium or format, as long as you give appropriate credit to the original author(s) and the source, provide a link to the Creative Commons license, and indicate if changes were made. The images or other third party material in this article are included in the article's Creative Commons license, unless indicated otherwise in a credit line to the material. If material is not included in the article's Creative Commons license and your intended use is not permitted by statutory regulation or exceeds the permitted use, you will need to obtain permission directly from the copyright holder. To view a copy of this license, visit http://creativecommons.org/ licenses/by/4.0/.

(C) The Author(s) 2019 